\title{
Organic Dyes Containing Coplanar Dihexyl-Substituted Dithienosilole Groups for Efficient Dye-Sensitised Solar Cells
}

\author{
Ciaran Lyons, ${ }^{1}$ Neelima Rathi, ${ }^{2}$ Pratibha Dev, ${ }^{1}$ Owen Byrne, ${ }^{1}$ Praveen K. Surolia, ${ }^{1}$ \\ Pathik Maji, ${ }^{1}$ J. M. D. MacElroy, ${ }^{1}$ Aswani Yella, ${ }^{3}$ Michael Grätzel, ${ }^{3}$ Edmond Magner, ${ }^{2}$ \\ Niall J. English, ${ }^{1}$ and K. Ravindranathan Thampi ${ }^{1}$ \\ ${ }^{1}$ SFI Strategic Research Cluster in Solar Energy Conversion, UCD School of Chemical and Bioprocess Engineering, \\ University College Dublin, Dublin 4, Ireland \\ ${ }^{2}$ SFI Strategic Research Cluster in Solar Energy Conversion, Department of Chemical Sciences and Bernal Institute, \\ University of Limerick, Limerick, Ireland \\ ${ }^{3}$ Laboratoire de Photonique et Interfaces (LPI), Ecole Polytechnique Fédérale de Lausanne, 1015 Lausanne, Switzerland
}

Correspondence should be addressed to Edmond Magner; edmond.magner@ul.ie, Niall J. English; niall.english@ucd.ie, and K. Ravindranathan Thampi; ravindranathan.thampi@ucd.ie

Received 20 October 2016; Accepted 20 February 2017; Published 4 May 2017

Academic Editor: Bill Pandit

Copyright (C) 2017 Ciaran Lyons et al. This is an open access article distributed under the Creative Commons Attribution License, which permits unrestricted use, distribution, and reproduction in any medium, provided the original work is properly cited.

A chromophore containing a coplanar dihexyl-substituted dithienosilole (CL1) synthesised for use in dye-sensitised solar cells displayed an energy conversion efficiency of $6.90 \%$ under AM 1.5 sunlight irradiation. The new sensitiser showed a similar fill factor and open-circuit voltage when compared with N719. Impedance measurements showed that, in the dark, the charge-transfer resistance of a cell using CL1 in the intermediate-frequency region was higher compared to N719 (69.8 versus $41.3 \Omega$ ). Under illumination at AM 1.5G-simulated conditions, the charge-transfer resistances were comparable, indicative of similar recombination rates by the oxidised form of the redox couple. The dye showed instability in ethanol solution, but excellent stability when attached to $\mathrm{TiO}_{2}$. Classical molecular dynamics indicated that interactions between ethanol and the dye are likely to reduce the stability of CL1 in solution form. Time-dependent density functional theory studies were performed to ascertain the absorption spectrum of the dye and assess the contribution of various transitions to optical excitation, which showed good agreement with experimental results.

\section{Introduction}

Dye-sensitised solar cells (DSSCs) [1] have the distinct advantage of being responsive to low and diffuse light levels, as well as to the light incident under acute irradiation angles. This renders the technology particularly suitable for indoor situations and other similar applications where the incident light is confined to a select band in the visible spectrum, which may be the characteristic output of a certain light source. There, it is possible to tune the spectral sensitivity of DSSC as the light-harvesting function of the cell is separated from the semiconductor, unlike in inorganic solar cells, and is taken up by a sensitiser. The standard and most studied sensitisers for making DSSC are ruthenium dyes with a reported maximum efficiency of $11.9 \%$ [2]. Although the DSSC is optimal for room interiors and vertical façade positions, its certified solar-to-electric power conversion efficiency (PCE) under standard air mass 1.5 (AM 1.5) reporting conditions $\left(1000 \mathrm{~W} / \mathrm{m}^{2}\right.$ solar light intensity and $\left.298 \mathrm{~K}\right)$ is still a factor of 2 below that of $\mathrm{Si}$ solar cells. Much effort has been expended in developing more efficient dyes [3,4]. However, $\mathrm{Ru}$ is expensive, has limited availability, and has an undesirable environmental impact when used in large amounts. A newer and increasingly emerging area of solar research lies in perovskite solar cells. One key challenge for perovskite commercialisation is stability. The light-sensitive material in these devices dissolves in the presence of water and decomposes at high temperature. Scientists must also address 
the possibility of lead contamination before these cells can be commercialised at large scale [3].

The development of new organic dyes has been the subject of much interest lately, especially metal-free dyes [5-7]. Organic dyes can be more versatile in their light absorption properties, owing to a larger number of molecular structure variations possible and in principle cheaper for mass scale production. They also possess higher molar extinction coefficients allowing efficient light harvesting using thinner layers when compared to Ru dyes. Porphyrins and phthalocyanines containing inexpensive metal atoms also have attracted considerable attention in the recent years [8, 9]. Recent reports have described a porphyrin-based dye in combination with a Co-complex containing electrolyte, a redox mediator exhibiting higher reduction potentials than that of $\mathrm{I}_{3}{ }^{-}$, which has displayed the highest efficiency to date of $13 \%$, as well as over $14 \%$ from a DSSC cophotosensitised with an alkoxysilyl-anchor dye and a carboxy-anchor organic dye [5-7]. Another reason for developing organic dyes is the industrial and architectural preferences for specific dye colours such as green, bright red, golden, and blue, when conceiving new buildings with integrated photovoltaics and designing newer interior designs. Indeed, industry is even willing to compromise slightly on solar cell efficiency for desired colour characteristics. This confers to organic dye research a rather compelling new impetus and scope.

In general, organic dyes consist of three segments: a donor, a linker, and an acceptor group. Much research has been performed on altering the nature of each of these groups with the aim of tuning the dyes' absorption spectrum in the visible spectral region. Synthetic chemists increasingly turn to molecular structures based on the current understanding of dyes' structure-property relationships. The introduction of long-chain alkyloxy groups in the dye structure is suggested to generally retard the charge recombination process [10]. Donor- $\pi$-bridge-acceptor (D- $\pi$-A) sensitisers, endowed with such groups, recently reached opencircuit voltage $\left(V_{\mathrm{oc}}\right)$ values exceeding $0.8 \mathrm{~V}$ when used with $\mathrm{Co}(\mathrm{II} / \mathrm{III})$ tris(bipyridyl) redox electrolytes. However, the energy conversion efficiencies of these dyes remained in the 6.7 to $9.6 \%$ range because of their insufficient solar light harvesting, resulting in low photocurrents $[10,11]$. The quest for newer dyes is therefore very challenging. In fact, dyes with narrower spectral bands still may find use in DSSC devices destined for indoor applications, where the available spectrum is usually influenced by indoor lighting systems.

Five-membered heterocycles containing silicon have also attracted attention recently, in particular, silole derivatives with a 2,2'-bithiophene group connected through a silicon atom. $\mathrm{Si}$, an abundant tetravalent element like $\mathrm{C}$ and widely used in organic synthesis, is thus a natural choice for organic sensitisers. Dithienosilole derivatives have been used in many optoelectronic devices, such as light emitting diodes [12], whilst dithienosilole-based polymers have been used in polymer solar cells [13]. There have been a few reports on the use of these materials in DSSCs, too. Ko et al. described the synthesis of silole-spaced triarylamine derivatives containing combinations of phenyl and methyl groups attached to silicon, with a PCE of $7.50 \%[14,15]$. Lin et al. reported a coplanar diphenyl-substituted dithienosilole dye with an efficiency of $7.60 \%$. The additional O-hexyl donor groups were added to the triphenylamine donor group to provide increased electron donor capabilities $[14,15]$. However, these compounds possessed increased conjugation and lowered LUMO (lowest unoccupied molecular orbital) levels. Coplanarity of the $\pi$-spacer was obtained by bridging the two thiophene units with a silicon atom, leading to more effective rates of electron transfer. To our knowledge, there have been no reports to date on the effects of adding large alkyl chains to the silicon group.

Here, we report a dithienosilole dye (Scheme 1) containing alkyl chains to help prevent aggregation of the dye sensitiser. The brightly red-coloured dye showed a good power conversion efficiency of $6.90 \%$ under 1 sun, in the absence of any additional electron donor groups. Electrochemical impedance spectroscopy (EIS) was used to study the chargetransfer properties of the dye-sensitised solar cell [16-20]. Time-dependent density functional theory (TD-DFT) was used to calculate the absorption spectra and compare it with experimental spectra. On exposure to ethanol for a week in a dye bath, the dye showed a decrease in efficiency to $5.83 \%$ and the colour of the dye bath went from the bright fluorescent red to a dull brown. Cell performance and UV-Vis absorption tested over time are shown in Supporting Information available online at https://doi.org/10.1155/2017/ 7594869. However, DSSCs made using this dye and a standard iodide-tri-iodide electrolyte still showed a stable incident photon-to-current efficiency (IPCE) value even after a month. Computational studies using classical molecular dynamics (MD) were performed to provide an insight into solvent effects and investigate hydrogen bonding between the dye and the ethanol medium.

\section{Experimental Section}

2.1. Materials. The following materials were used as received: 1-butyl-3-methyl imidazolium iodide (BMII, Merck 4.90187.0100) and guanidinium thiocyanate (GuSCN, Merck 8.20613.0250). Ethanol was purchased from Lennox, Dublin. All other chemicals were purchased and used as received from Sigma-Aldrich. Toluene was distilled under sodium benzophenone and stored under nitrogen. Dimethylformamide was dried using barium oxide. Titanium dioxide paste (Ti-Nanooxide D20), electrolyte (Iodolyte AN-50), Surlyn film (Meltonix 1170-60), and fluorine-doped tin oxide glass slides (TCO30-8, $\sim 8 \mathrm{ohm} /$ square) were purchased from Solaronix SA (Aubonne, Switzerland). A second "light scattering" paste of particle size 150-250 nm was purchased from DyeSol Ltd. (WER 2-0).

Three types of $\mathrm{TiO}_{2}$ pastes were used to make cells, including the commercially purchased samples. The first was a "transparent" type containing $20 \mathrm{~nm}$ particles of $\mathrm{TiO}_{2}$ prepared from Evonik P25 powder using a standard fabrication procedure [21]. Ethyl cellulose (Fluka, \#46080) and anhydrous terpineol (Fluka, \#46070) were used as received to make a paste. A second paste of particle size $150-250 \mathrm{~nm}$ and purchased from DyeSol Ltd. (WER 2-0) was used to form a light scattering layer. Both pastes were screen printed with a 


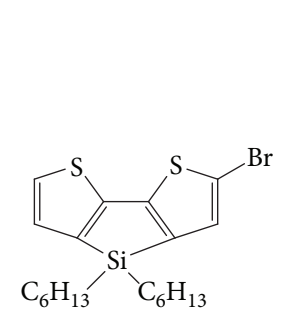

(A)

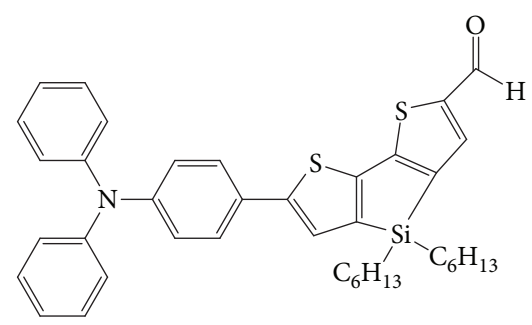

(C)

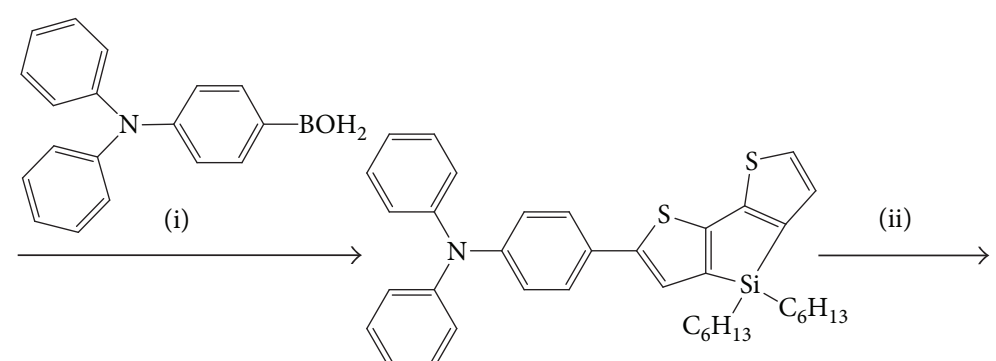

(B)

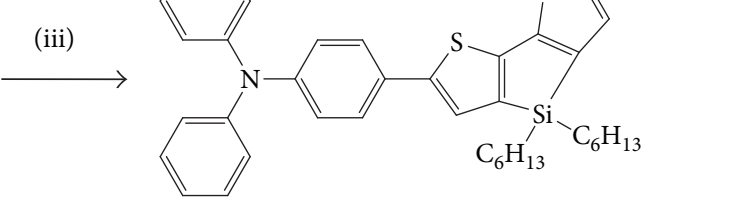

$(\mathrm{CL}-1)$

Scheme 1: Reagents and conditions: (i) 4-(diphenylamino) phenylboronic acid, palladium(II) acetate, cesium carbonate, toluene, reflux, $24 \mathrm{~h}$, (ii) $\mathrm{POCl}_{3}, \mathrm{DMF}, 90^{\circ} \mathrm{C}, 24 \mathrm{~h}$, and (iii) 2-cyanoacetic acid, piperidine, acetonitrile, reflux, $4 \mathrm{~h}$.

90T mesh to yield electrodes of approximately $15 \mu \mathrm{m}$ thickness $(10 \mu \mathrm{m}$ transparent layer and a $5 \mu \mathrm{m}$ scattering layer). The standard liquid electrolyte used was labelled E1 [22] and was comprised of $0.03 \mathrm{M}$ iodine, $0.1 \mathrm{M}$ guanidinium thiocyanate, $0.5 \mathrm{M}$ 4-tert-butylpyridine, and $0.6 \mathrm{M}$ BMII in an acetonitrile : valeronitrile solvent mixture ( 85 : 15 by volume). The Solaronix paste was used without light scattering layers in certain experiments, where cell efficiencies were not considered the primary objective.

2.2. Dye Characterisation. Absorption and emission spectra of the dye were obtained, both in the dissolved form as well as in the chemisorbed state on $\mathrm{TiO}_{2}$ surface. For experiments with $\mathrm{TiO}_{2}$, a mixture was prepared using $100 \mu \mathrm{l}$ Ti-Nanooxide D20, $35 \mu$ l polyethylene glycol (PEG), and $100 \mu \mathrm{l}$ of $1 \%$ Tween- 80 in water, which were mixed together to obtain a gel. The gel was spread onto an FTO glass slide and left to dry for $30 \mathrm{~min}$ after which the electrode was calcined at $450^{\circ} \mathrm{C}$ for 30 minutes. The adsorption of CL1 dye was performed by immersing the $\mathrm{TiO}_{2}$ electrodes in CL1 $(0.57 \mathrm{mM})$ solution in ethanol overnight $(18 \mathrm{~h})$. The electrodes were then rinsed with ethanol and dried in air. Solution-based absorption and emission spectra were recorded on a Varian Cary 300 UV-Visible and a Cary eclipse fluorescence spectrophotometer, respectively, using quartz cuvettes. The absorption spectrum of the anchored dye was obtained on a UV-1800 Shimadzu spectrophotometer.

A Perkin Elmer Spectrum 100 FT-IR spectrometer was used to record ATR-FTIR spectra at a resolution of $2 \mathrm{~cm}^{-1}$. The spectra reported represent averages of 100 scans. A CHI800 potentiostat was used for cyclic-voltammetry measurements. Dye-immobilised $\mathrm{TiO}_{2}$, Pt wire, and $\mathrm{Ag} / \mathrm{AgCl} /$ $\mathrm{KCl}$ were used as the working, counter, and reference electrodes, respectively. Solutions were bubbled with $\mathrm{N}_{2}$ gas and kept under an $\mathrm{N}_{2}$ atmosphere during experiments.
Electrochemical impedance spectroscopy was performed using an impedance analyser (Solartron analytical, 1260) connected to a potentiostat (Solartron Analytical, 1287). EIS spectra were measured under illumination and at applied bias voltage equivalent to the open-circuit voltage $\left(V_{\text {oc }}\right)$ of the device in the dark over the frequency range of 0.1 to $10^{5} \mathrm{~Hz}$ using a $10 \mathrm{mV}$ amplitude AC signal. Impedance spectra were fitted to an equivalent circuit model using ZView software (Scribner Associates Inc.).

${ }^{1} \mathrm{H}$ and ${ }^{13} \mathrm{C}$ NMR spectra were recorded using Bruker 300 and $400 \mathrm{MHz}$ instruments using the residual signals $\delta=7.26 \mathrm{ppm}$ and $77.0 \mathrm{ppm}$ for $\mathrm{CDCl}_{3}$ and $\delta=2.50 \mathrm{ppm}$ and $39.4 \mathrm{ppm}$ for $\left[\mathrm{D}_{6}\right]$-DMSO.

2.3. General Synthetic Procedure. The synthetic procedure for the preparation of compound A has been described previously [23]. The synthesis of B was achieved through Suzuki coupling between the bromo-silole derivative and triphenylamine-boronic acid. Aldehyde addition was performed using Vilsmeier formylation using phosphorus oxychloride to yield C. Claisen condensation between cyano2 -acetic and the aldehyde in the presence of piperidine yielded CL-1 as a purple solid with a yield of $41 \%$.

2.4. 5-[N,N-Bis(phenylamino)phenyl]-3,3'-dihexyllsilylene2,2'-bithiophene (B). Compound A (0.59 g, $1.34 \mathrm{mmol}), 4$ (diphenylamino) phenylboronic acid $(0.469 \mathrm{~g}, 1.61 \mathrm{mmol})$, palladium(II) acetate $(0.030 \mathrm{~g}, 0.134 \mathrm{mmol})$, and cesium carbonate $(2.638 \mathrm{~g}, 8.09 \mathrm{mmol})$ were dissolved in toluene $(75 \mathrm{ml})$. The reaction mixture was refluxed overnight. The organic layer was extracted using $\mathrm{CH}_{2} \mathrm{Cl}_{2}$ and washed with $\mathrm{H}_{2} \mathrm{O}$ and then dried over $\mathrm{Na}_{2} \mathrm{SO}_{4}$. The solvent was removed by rotary evaporation. The crude product obtained was then purified using column chromatography (petroleum ether/ $\mathrm{CH}_{2} \mathrm{Cl}_{2}=6 / 1$ ) to yield compound $\mathrm{B}$ as a yellow wax 


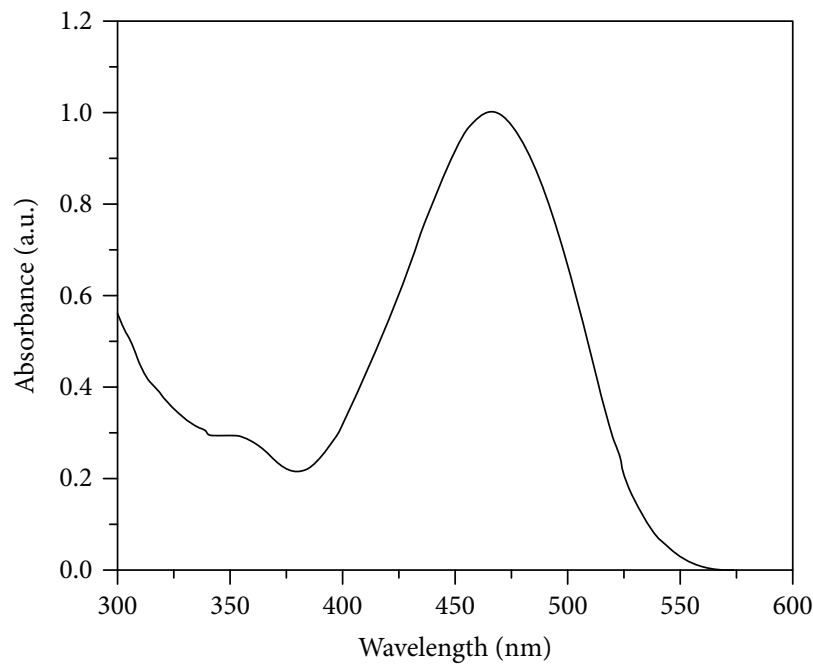

(a)

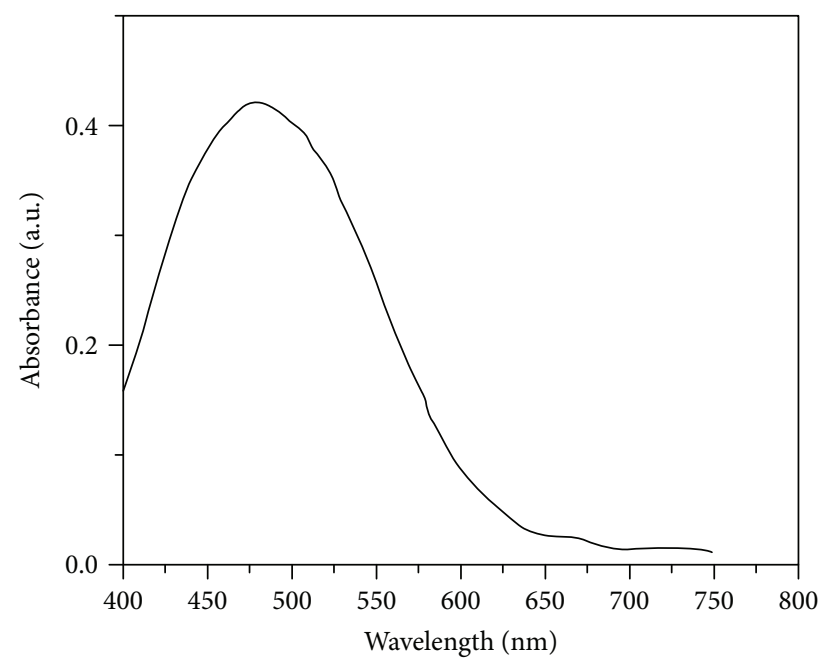

(b)

FIGURE 1: Absorption spectrum of CL1 dye showing an absorption band at $468 \mathrm{~nm}$ (a) in ethanol $(0.057 \mathrm{mM})$ and (b) adsorbed on a TiO film showing a red shift indicative of interactions between the dye molecule and the semiconductor.

with $61 \%$ yield. ${ }^{1} \mathrm{H}$ NMR $\left(\mathrm{CDCl}_{3}, 400 \mathrm{MHz}\right): \delta$ ppm 7.46 $(2 \mathrm{H}, J=12 \mathrm{~Hz}, \mathrm{~d}), 7.29-6.97(15 \mathrm{H}, \mathrm{m}), 1.45-1.16(16 \mathrm{H}$, $\mathrm{m}), 0.95-0.87(\mathrm{~m}, 4 \mathrm{H})$, and $0.87-0.79(6 \mathrm{H}, \mathrm{m}) ;{ }^{13} \mathrm{C} \mathrm{NMR}$ ([D $]$-DMSO, $100 \mathrm{MHz}): \delta$ ppm 149.42, 147.61, 147.51, $146.89,144.78,143.12,141.05,129.63,129.27,129.17,128.90$, $126.38,124.95,124.85,124.39,124.14,123.90,122.98,122.64$, $32.85,31.42,24.16,22.55,14.07$, and 11.91 .

2.5. 5-[N,N-Bis(phenylamino)phenyl]-5'-formyl-3,3'-hexylsilylene2,2'-bithiophene $(C)$. Compound B $(0.50 \mathrm{~g}, 0.825 \mathrm{mmol})$ was dissolved in DMF $(50.00 \mathrm{ml})$. At $0^{\circ} \mathrm{C}, \mathrm{POCl}_{3}(0.184 \mathrm{ml}$, $1.956 \mathrm{mmol}$ ) was added to this solution and the mixture was stirred at $90^{\circ} \mathrm{C}$ overnight. The organic layer was extracted using $\mathrm{CH}_{2} \mathrm{Cl}_{2}$ and washed with $\mathrm{H}_{2} \mathrm{O}$ and before drying over $\mathrm{Na}_{2} \mathrm{SO}_{4}$. The solvent was removed by rotary evaporation. The crude product was then purified using column chromatography (petroleum ether $/ \mathrm{CH}_{2} \mathrm{Cl}_{2}=4 / 1$ ) to yield compound $\mathrm{C}$ as an orange wax in $74 \%$ yield. ${ }^{1} \mathrm{H} \mathrm{NMR}\left(\mathrm{CDCl}_{3}\right.$, $400 \mathrm{MHz}): \delta$ ppm $9.85(1 \mathrm{H}, \mathrm{s}), 7.69(1 \mathrm{H}, \mathrm{s}), 7.47(2 \mathrm{H}$, $J=8 \mathrm{~Hz}, \mathrm{~d}), 7.30-7.21(5 \mathrm{H}, \mathrm{m}), 7.14-7.03(8 \mathrm{H}, \mathrm{m}), 1.44-$ $1.19(16 \mathrm{H}, \mathrm{m}), 0.99-0.91(4 \mathrm{H}, \mathrm{m})$, and $0.88-0.79(6 \mathrm{H}, \mathrm{m})$;

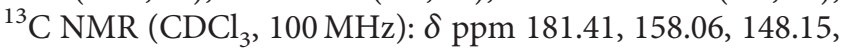
$147.04,146.77,146.29,145.03,143.20,140.68,138.49$, $132.94,128.34,126.75,125.72,124.00,123.70,122.34$, $122.31,119.94,31.77,30.34,23.06,21.49,13.02$, and 10.70 .

2.6. 3-[5-[N,N-Bis(phenylamino)phenyl]-3,3'-dihexylsilylene2,2'-bithiophene-5'-yl]-2-cyanoacrylic Acid (CL-1). At first, compound C $(0.05 \mathrm{~g}, 0.883 \mathrm{mmol}), 2$-cyanoacetic acid $(0.02 \mathrm{~g}, 0.258 \mathrm{mmol})$, and a drop of piperidine were dissolved in acetonitrile $(10 \mathrm{ml})$. This mixture was then refluxed for $2.5 \mathrm{~h}$. After removal of the solvent, the crude product was purified using column chromatography $\left(\mathrm{CH}_{2} \mathrm{Cl}_{2} / \mathrm{MeOH}=30 / 1\right)$ to yield $\mathrm{Cl}-1$ as a purple solid with $41 \%$ yield. ${ }^{1} \mathrm{H}$ NMR $\left(\mathrm{CDCl}_{3}, 400 \mathrm{MHz}\right): \delta$ ppm $8.05(1 \mathrm{H}, \mathrm{s})$, $7.67(1 \mathrm{H}, \mathrm{s}), 7.59(2 \mathrm{H}, J=12 \mathrm{~Hz}, \mathrm{~d}), 7.52(1 \mathrm{H}, \mathrm{s}), 7.38-7.28$
(4H, m), 7.12-6.94 (8H, m). 1.39-1.10 (16H, m), 0.99-0.89 $(4 \mathrm{H}, \mathrm{m})$, and $0.84-0.73(6 \mathrm{H}, \mathrm{m})$; HRMS (TOF-MS-ESI) $\mathrm{m} / \mathrm{z}$ : $699.2535[\mathrm{M}+]$; calculated for $\mathrm{C}_{42} \mathrm{H}_{43} \mathrm{~N}_{2} \mathrm{O}_{2} \mathrm{~S}_{2} \mathrm{Si}[\mathrm{M}+]$ : 699.2535 .

2.7. Cell Fabrication and Characterisation. DSSCs were manufactured as described previously [24]. Screen printing was used to deposit layers of $\mathrm{TiO}_{2}$ on a fluorine-doped tin oxide (FTO) conducting transparent glass substrate. In all cases, a nonporous, dense blocking underlayer of $\mathrm{TiO}_{2}$ was deposited first on the FTO substrate via $\mathrm{TiCl}_{4}$ treatment [21] in order to reduce charge recombination, prior to screen printing. The $\mathrm{TiO}_{2}$ paste was then printed on the $\mathrm{TiCl}_{4}$ treated glass using a Tiflex Ltd., France, screen printer and involved several cycles. After deposition of each layer, the films were kept in an ethanol saturated chamber for $6 \mathrm{~min}$ followed by drying at $125^{\circ} \mathrm{C}$ for $6 \mathrm{~min}$, whilst the final sintering involved gradual heating in an oven at $325^{\circ} \mathrm{C}(5 \mathrm{~min}), 375^{\circ} \mathrm{C}(5 \mathrm{~min}), 450^{\circ} \mathrm{C}$ $(15 \mathrm{~min})$, and $500^{\circ} \mathrm{C}(30 \mathrm{~min})$. After sintering, a layer of $\mathrm{TiCl}_{4}$ was deposited followed by sintering at $500^{\circ} \mathrm{C}$ for $30 \mathrm{~min}$. The $\mathrm{TiO}_{2}$ active area was $0.283 \mathrm{~cm}^{2}(6 \mathrm{~mm}$ diameter circular spot). The sintered electrodes were placed in a dye bath of N719 (benchmark dye as supplied by Dyesol Ltd., without further purification) dissolved in an acetonitrile : tert-butyl alcohol: THF mixture (vol $4.5: 4.5: 1$ ) or Si dye (CL-1) in ethanol at a concentration of $200 \mu \mathrm{M}$ for $16-20$ hours. The counter electrode was prepared with a thin film of Pt catalyst deposited via a drop of $\mathrm{H}_{2} \mathrm{PtCl}_{6}$ solution $(2 \mathrm{mg}$ Pt content in $1 \mathrm{ml}$ ethanol) and heat treated at $400^{\circ} \mathrm{C}$ for 15 minutes. The dye-coated $\mathrm{TiO}_{2}$ electrode and Pt-coated counter electrode were sandwiched together and sealed using a Bynel polymer gasket $(50 \mu \mathrm{m}$ thick). Electrolyte was filled into the space between the two electrodes through a hole in the counter electrode via the vacuum back-filling method. The back hole was then heat sealed with a thin piece $(0.1 \mathrm{~mm}$ thick $)$ of glass, again with Bynel. 


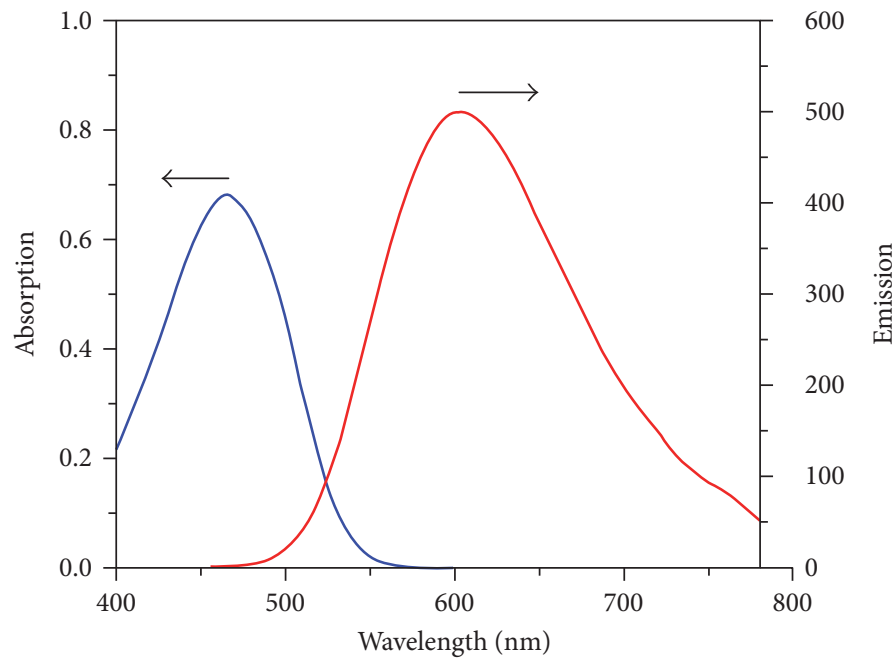

Figure 2: Absorption (blue line) and emission (red line) spectra of CL1 in ethanol in arbitrary units showing values of $468 \mathrm{~nm}$ and $618 \mathrm{~nm}$, respectively.

2.8. Electrooptical Characterisation. Current/voltage $(I-V)$ curves, open-circuit voltage $\left(V_{\text {oc }}\right)$, short-circuit current density $\left(J_{\mathrm{sc}}\right)$, and the fill factor $(\mathrm{FF})$ were measured using a Newport 91195A-1000 solar simulator and Newport 69920 Arc Lamp Power Supply. A Newport 81088A air mass filter was placed before the output of the solar simulator to simulate the AM 1.5 spectrum. $I-V$ measurements were recorded with a GAMRY Instruments potentiostat. Spectral response and incident photon-to-current efficiency (IPCE) measurements were made with using a solar cell spectral response/QE/IPCE measurement system (Solar Cell Scan 100 (SCS100)-Gilden Photonics Ltd.).

2.9. Time-Dependent Density Functional Theory. The Cl-1 dye was modelled using Discovery Studio Visualizer package (Accelrys, San Diego, CA). Ground-state structural optimisation and excited-state calculations for the isolated dye and the dye in complex with a titania nanoparticle were then performed using Gaussian'09 using the linear response approach [25]. The two hexyl groups in the side chains were replaced by the methyl groups to reduce computational time. This should not affect the results, as these side chains do not participate in the photoexcitation of the dye. The transitions of interest are predominantly charge-transfer in character. Such excitations are better described by conventional hybrid and range-separated $x c$-functionals $[26,27]$. For the CL1 dye, two approximations were used: (a) Becke-3 Lee-Yang-Parr (B3LYP) hybrid functional [28-30] and (b) Coulombattenuated functional, CAM-B3LYP [31]. The standard $6-31 \mathrm{G}^{*}$ basis set, which provides a very good compromise between the accuracy and computational time, was also used. The calculations were performed in two stages:

(1) Structural optimisation was carried out for the isolated dye using both functionals. After geometry optimisation, TD-DFT was used to obtain the UV/Vis absorption spectra of the dye within the two functionals. The theoretical results were then compared

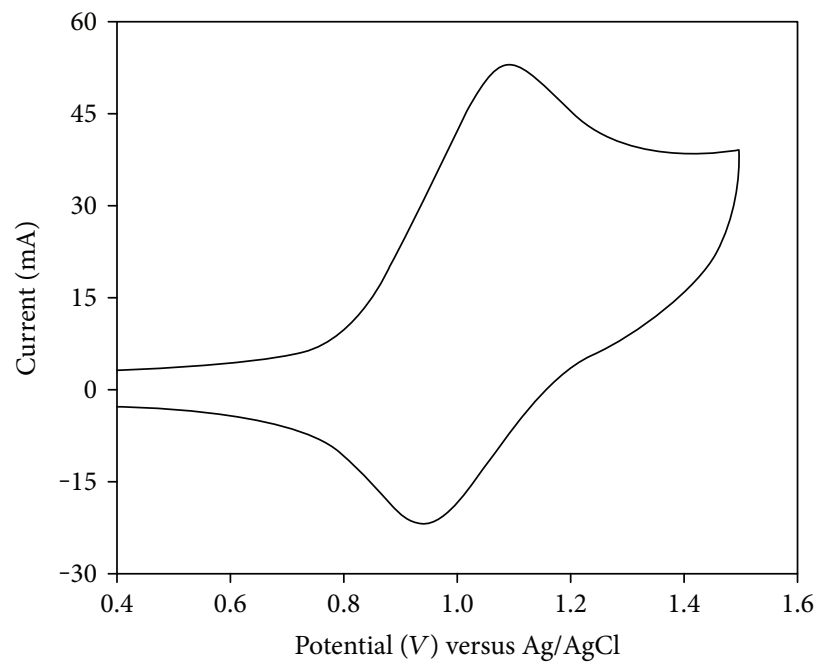

FIgURe 3: Cyclic voltammogram of adsorbed CL1 dye at a scan rate of $100 \mathrm{mV} / \mathrm{s}$, in $0.1 \mathrm{M} \mathrm{TBAPF} \mathrm{T}_{6}$ in acetonitrile showing quasi-reversible behaviour; the oxidation and reduction peaks can be attributed to the triphenylamine moieties and cyanoacrylic acid, respectively.

with experimental data to choose the most appropriate functional.

(2) The ground- and excited-state properties of the dyetitania complex were characterised using the optimal functional. To compare theoretical results with their experimental counterparts, solvent (ethanol) effects were added using the polarisable continuum solvation model (C-PCM) [32] in all calculations. The complex was created by attaching the dye to a 114 atom-containing nanoparticle $\mathrm{TiO}_{2}$ cut from an anatase (101) surface. This cluster geometry has been employed in earlier studies and demonstrated that the lowest excitation energy was in agreement with the experimental semiconductor bandgap [33-37]. 
TABLE 1: Experimental data of electrochemical and spectroscopic properties of the CL1 dye.

\begin{tabular}{lccccc}
\hline$\lambda_{\mathrm{abs}, \max }(\mathrm{nm})$ & $\varepsilon\left(\mathrm{M}^{-1} \mathrm{~cm}^{-1}\right)$ & $\lambda_{\mathrm{em}, \max }(\mathrm{nm})$ & $E_{\mathrm{ox}}(\mathrm{V})($ versus NHE) & ${ }^{\mathrm{a}} E_{0-0}(\mathrm{eV})$ & $E_{\mathrm{LUMO}}(\mathrm{V})(\mathrm{versus}$ NHE$)$ \\
\hline 468 & 30,000 & 618 & 1.28 & 2.29 & -1.01 \\
\hline
\end{tabular}

${ }^{a}$ The LUMO (lowest unoccupied molecular orbital) level of the dye was calculated using equation $E_{\mathrm{ox}}-E_{0-0}[47,48]$, where $E_{0-0}$ is the zeroth-zeroth transition energy of the dye estimated from the intersection between the absorption and emission spectra of the dye (Figure 2).

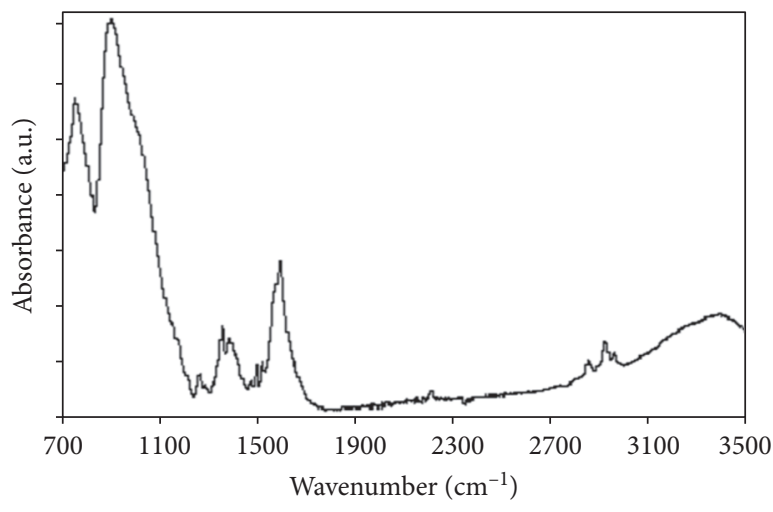

(a)

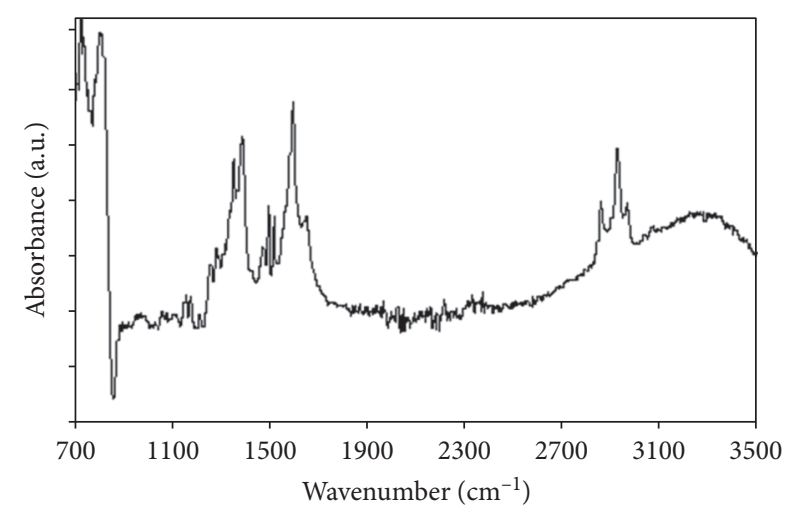

(b)

FIGURE 4: (a) ATR-FTIR spectrum of CL1 dye showing sharp phenyl and thiophene ring modes at 1517, 1491,1375 , and $1256 \mathrm{~cm}^{-1}$, whilst the C-N stretching mode of triarylamine appeared at $1348 \mathrm{~cm}^{-1}$. (b) ATR-FTIR spectrum of CL1 dye adsorbed on TiO 2 showing the $v_{\text {asym }}\left(\mathrm{COO}^{-}\right)$and $v_{\text {sym }}\left(\mathrm{COO}^{-}\right)$stretching modes of carboxylate linker groups at 1590 and $1382 \mathrm{~cm}^{-1}$, respectively, whilst the $\mathrm{C} \equiv \mathrm{N}$ stretch frequency was unchanged at $2209 \mathrm{~cm}^{-1}$.

Geometrical optimisation of the isolated titania cluster was performed under CAM-B3LYP. The groundstate structure of the nanoparticle was then used to create the CL1 dye-titania complex. Once the complexed structure was also optimised, TD-DFT calculations were performed to obtain the UV/Vis absorption spectra for the dye-titania complex.

2.10. Molecular Dynamics. Classical MD simulations were used to investigate and quantify hydrogen-bond lifetimes with ethanol as a solvent. Given the small-molecule nature of the dye, the MMFF94 force field was utilized [38]. All MD calculations were performed using the MOE software package [39]. Nonbonded interactions were treated using a twin-range method [40], with short and long cut-off radii of 10 and $12 \AA$, respectively, with reaction field electrostatics [41] with a cut-off radius of $15 \AA$. The dielectric constant was set at the experimental value of 24.3 [42]. Following gasphase geometry optimisation, the dye was placed in the centre of a rectangular periodic box surrounded by 845 ethanol molecules under periodic boundary conditions (PBC) [43], relaxed via $\mathrm{MD}$ in the liquid state at $298 \mathrm{~K}$ and $1 \mathrm{~atm}$. Prior to $\mathrm{MD}$ under $\mathrm{PBC}$, the heavy atoms in the simulation box were fixed and the system was relaxed by energy minimization. This was followed by "heating" of the system to $300 \mathrm{~K}$ in $25 \mathrm{~K}$ increments by MD in stages of 10 ps duration in the NVT ensemble, using velocity assignments from the Maxwell-Boltzmann distribution at the start of each step. A production simulation was then carried out in the NPT ensemble for $100 \mathrm{ps}$, and bond lengths were constrained with a relative tolerance of $10^{-8}$ [43]. A time step of $1 \mathrm{fs}$ was used.
The period of the thermal and barostat reservoirs [43] was set to 1 and 5 ps, to allow for relatively weak coupling.

\section{Results and Discussion}

3.1. Absorption and Emission Spectra. The absorption spectrum of the CL1 dye in ethanol (Figure 1) showed a broad absorption band at $468 \mathrm{~nm}$ with a molar extinction coefficient $(\varepsilon)$ of $30 \times 10^{3} \mathrm{M}^{-1} \mathrm{~cm}^{-1}$, which arises from $\pi-\pi^{*}$ charge-transfer transition $[15,44,45]$. The absorption spectra of adsorbed dyes on $\mathrm{TiO}_{2}$ displayed a slight red shift in the absorption bands, indicative of interactions between the dye molecule and the semiconductor. The dye in solution exhibits considerable emission characteristics, when excited with light of suitable wavelengths. The fluorescence spectrum of the CL1 dye in ethanol shows an emission peak centred at $618 \mathrm{~nm}$ upon excitation at $468 \mathrm{~nm}$. The absorption spectrum of CL1 dye in ethanol, shown in Figure 1(a), is presented together with its fluorescence spectrum in Figure 2, which shows a stoke shift of $150 \mathrm{~nm}$.

3.2. Cyclic Voltammetry. Cyclic voltammetry was used to measure the ground-state oxidation potential $\left(E_{\mathrm{ox}}\right)$ of the dye. The cyclic voltammogram (Figure 3 ) of the dye showed quasi-reversible behaviour; the oxidation and reduction peaks can be attributed to the triphenylamine moieties and cyanoacrylic acid, respectively [15]. The value of $E_{\mathrm{ox}}$ of the dye, $1.28 \mathrm{~V}$ (versus NHE), is more positive (Table 1) than the redox potential $(0.4 \mathrm{~V}$ versus NHE) [46] of the iodide/triiodide couple. Thus, the oxidised dye can be regenerated by $\mathrm{I}^{-}$in the electrolyte enabling efficient charge separation. The LUMO energy level of the dye, $-1.01 \mathrm{~V}$ 


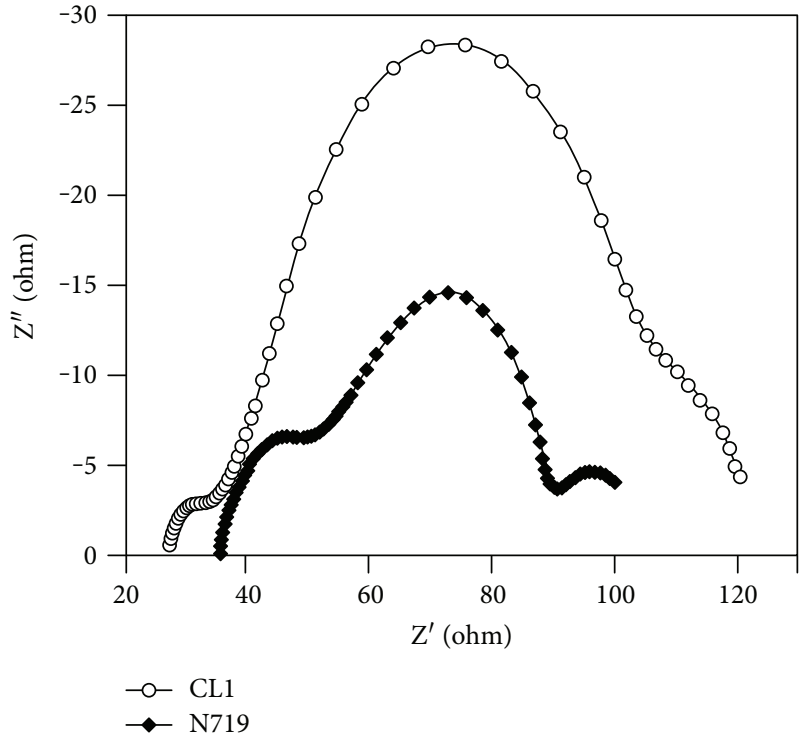

(a)

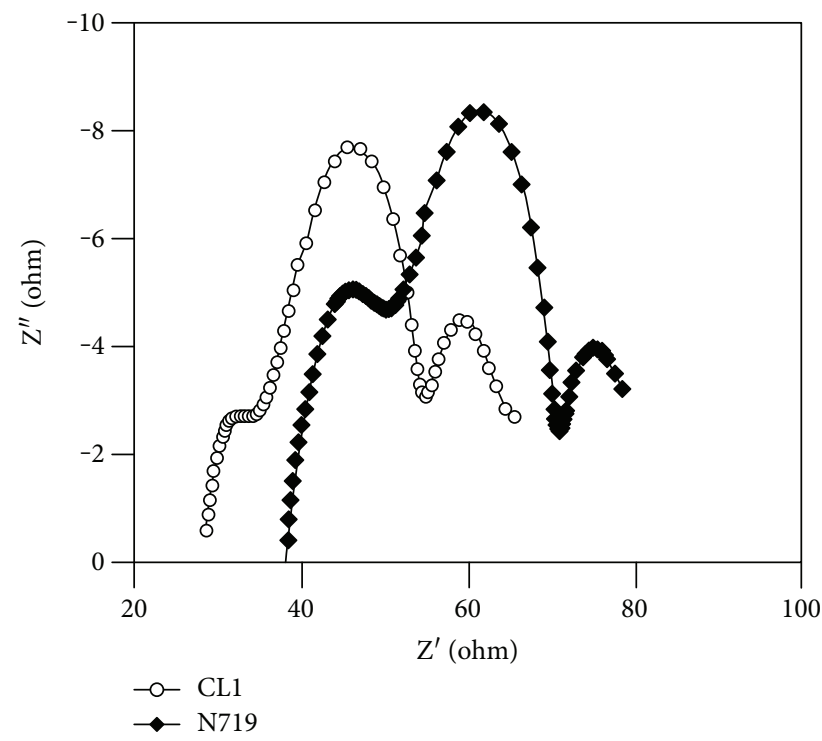

(c)

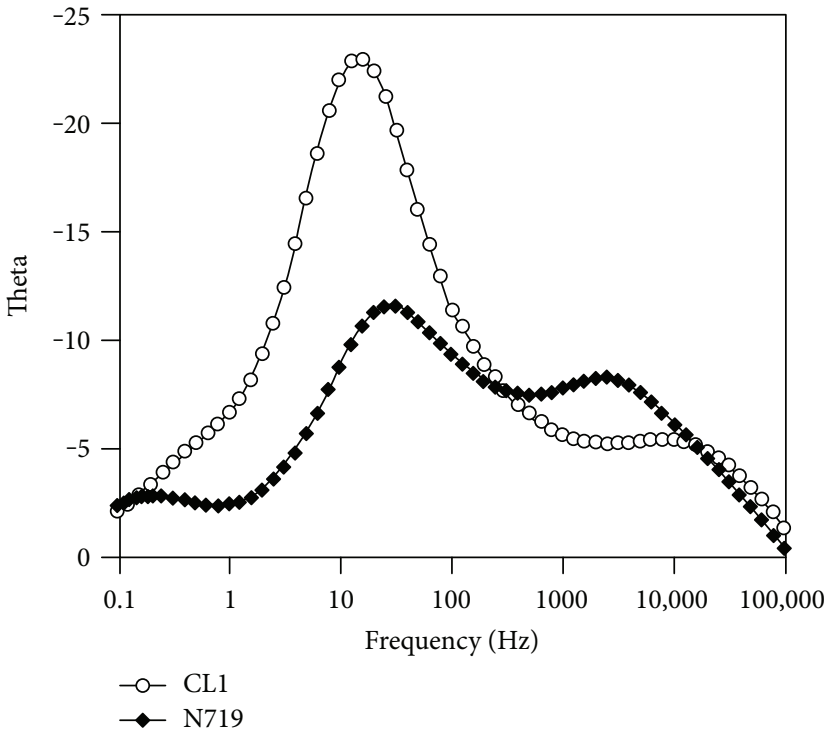

(b)

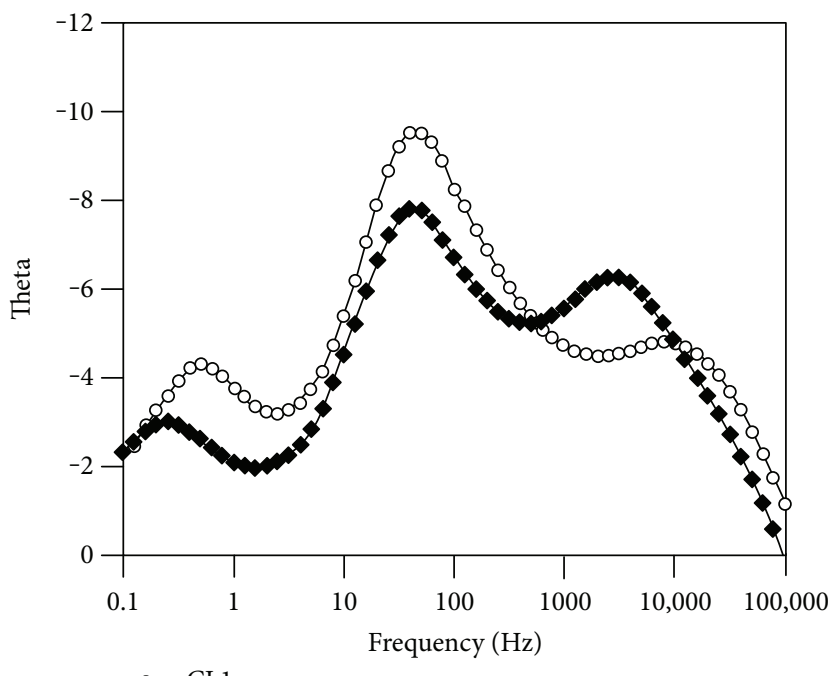

$-0-$ CL1

$\rightarrow$ N719

Figure 5: Nyquist ((a) and (c)) and Bode phase ((b) and (d)) plots of N719 and CL1 dye sensitised DSSCs in the dark ((a) and (b)) at -0.67 V and under 1 sun illumination ((c) and (d)) at open-circuit voltages.

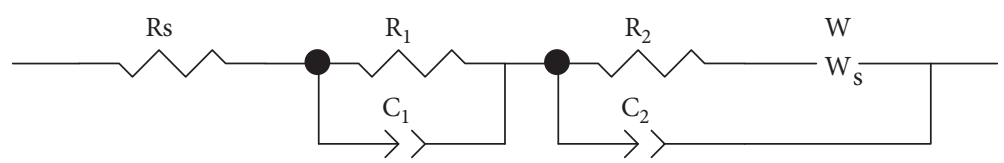

FIgURE 6: Equivalent circuit used to fit EIS data.

(versus NHE), is more negative than the conduction band edge $\left(-0.5 \mathrm{~V}\right.$ versus NHE) [46] of $\mathrm{TiO}_{2}$ (Table 1), thus providing sufficient driving force to inject an electron from the excited dye to the conduction band of $\mathrm{TiO}_{2}$.

3.3. ATR-FTIR Spectra. ATR-FTIR spectra of the dye (Figure 4(a)) showed sharp phenyl and thiophene ring modes $[42,49,50]$ at $1517,1491,1375$, and $1256 \mathrm{~cm}^{-1}$, whilst the $\mathrm{C}-\mathrm{N}$ stretching mode of triarylamine appeared at $1348 \mathrm{~cm}^{-1}$. Stretching modes assigned to $v(\mathrm{C}=\mathrm{O}), v$ $(\mathrm{Si}-\mathrm{C})$, and $v(\mathrm{C}-\mathrm{H})$ stretch were observed at 1588,886 , and $2957 \mathrm{~cm}^{-1}$, respectively. The ATR-FTIR spectrum (Figure 4(b)) of adsorbed CL1 dye shows the $v_{\text {asym }}\left(\mathrm{COO}^{-}\right)$ and $v_{\text {sym }}\left(\mathrm{COO}^{-}\right)$stretching modes of carboxylate linker 
TABLE 2: Electronic device parameters obtained by fitting the EIS data to the equivalent circuit model (Figure 6).

\begin{tabular}{lcccc}
\hline DSC & Rs $(\Omega)$ & $\mathrm{R}_{1}(\Omega)$ & $\mathrm{R}_{2}(\Omega)$ & $\omega_{\max }(\mathrm{Hz})$ \\
\hline $\begin{array}{l}\text { AM 1.5 sunlight at an } \\
\text { intensity of 1 sun } \\
\left(1000 \mathrm{~W} / \mathrm{m}^{2}\right)\end{array}$ & & & & \\
$\quad$ CL1 & & & & \\
$\quad$ N719 & 28.7 & 6.8 & 19.7 & 31.6 \\
In dark & 38.1 & 10.7 & 22.6 & 39.8 \\
$\quad$ & & & & \\
$\quad$ N11 & 27.4 & 8.0 & 69.8 & 15.8 \\
$\quad$ N719 & 35.7 & 12.9 & 41.3 & 19.9 \\
\hline
\end{tabular}

groups at 1590 and $1382 \mathrm{~cm}^{-1}$, respectively [42, 49, 51]. The $\mathrm{C} \equiv \mathrm{N}$ stretch frequency was unchanged at $2209 \mathrm{~cm}^{-1}$. Possible binding modes between the carboxylate group and $\mathrm{TiO}_{2}$ can be either bidentate bridging or chelation [52]. As the chelation mode is known to be unstable [53], the bridging bidentate mode is more likely to occur.

3.4. Impedance Analysis. The electrochemical impedance spectra (Figure 5) were fitted to an equivalent circuit model [54-56], containing a constant phase element (CPE) and resistance $(R)$ (Figure 6). Rs is the resistance at the FTO/TiO 2 interface and $\mathrm{R}_{1}$ and $\mathrm{C}_{1}$ are the charge-transfer resistance and capacitance at the electrolyte/Pt-FTO interface. Variations in Rs arise from the electrical contacts and wiring of the device $[57,58] . \mathrm{R}_{2}$ and $\mathrm{C}_{2}$ are the charge recombination resistance and capacitance at the $\mathrm{TiO}_{2} /$ dye/electrolyte interface. The parameters obtained upon fitting the spectra to the equivalent circuit (Figure 6) are shown in Table 2.

The impedance spectra of N719 and the CL1-DSSC measured at $V_{\text {oc }}$ under illumination and in the dark at an applied bias voltage equivalent to $V_{\text {oc }}$ of the cell are shown in Figure 6. Three semi-circles were observed in the Nyquist plots over the frequency range of $0.1-10^{5} \mathrm{~Hz}$. The smaller semicircle in the high-frequency region is associated with charge transfer at the electrolyte/Pt-FTO interface; the larger semicircle in the middle-frequency region, to the electron transport and recombination mechanism at the $\mathrm{TiO}_{2} /$ dye/ electrolyte interface, whilst the low-frequency region semicircle may be attributed to diffusion of $\mathrm{I}_{3}{ }^{-}$in the electrolyte. The impedance values of the $\mathrm{TiO}_{2} /$ dye/electrolyte interface, represented by the semicircles at the intermediate-frequency region in the Nyquist plots, are much smaller under illumination than in the dark. Under illumination, and subject to solubility conditions [59], $\mathrm{I}_{3}{ }^{-}$is formed at the $\mathrm{TiO}_{2}$ /electrolyte interface by dye regeneration, whilst in the dark, $\mathrm{I}_{3}{ }^{-}$is produced at the counter electrode. This indicates that recombination of CB electrons is accelerated under illumination hence decreasing the electron lifetime in the $\mathrm{TiO}_{2}$ film. In the dark, the charge-transfer resistance of CL1 DSC $(69.8 \Omega)$, in the intermediate frequency region, was higher compared to N719 (41.3 $\Omega$ ); under illumination, the charge-transfer resistances were similar (6.8 and $10.7 \Omega$, for CL1 and N719, respectively), indicative of similar recombination rates for both dyes.

EIS Bode phase plots also exhibited two characteristic peaks under 1 sun and in the dark; the peak at higher
TABLE 3: Photovoltaic parameters of DSSC cells fabricated using CL-1 and N719 dyes recorded under simulated AM 1.5 sunlight at an intensity of 1 sun $\left(1000 \mathrm{~W} / \mathrm{m}^{2}\right)$.

\begin{tabular}{lcccc}
\hline Dye & $V_{\text {oc }}(\mathrm{V})$ & $J_{\text {sc }}\left(\mathrm{mA} / \mathrm{cm}^{2}\right)$ & FF & $\eta(\%)$ \\
\hline Si dye & 0.742 & 14.4 & 65 & 6.90 \\
N719 & 0.745 & 17.4 & 62 & 8.05 \\
\hline
\end{tabular}

frequency can be attributed to charge transfer at the counter electrode, whilst the peak in the middle-frequency region is associated with electron transfer at the $\mathrm{TiO}_{2}$ /dye/electrolyte interface. The characteristic middle-frequency peak of the Bode plot can be used to provide a measure of the charge recombination rate [60]. For simple circuits, the reciprocal of this frequency peak is a direct measure of the electron lifetime in $\mathrm{TiO}_{2}$; however, the relationship is more complex for the Randles circuit described in Figure 6. Under illumination, the midfrequency peak of the CL1-based DSC (Figure 5(d)) is slightly shifted to higher frequency compared to that of the N719 DSC, indicative of a shorter electron lifetime. This suggests a slightly lower rate of electron injection and lower charge collection efficiency for the CL1-based cell compared to the N719 cell, hence leading to a lower overall value of $J_{\mathrm{sc}}$.

3.5. Cell Efficiency Analysis. A PCE of $6.90 \%$ was achieved for the CL1-containing DSSC. The fill factor and open-circuit voltages $\left(V_{\text {oc }}\right)$ were similar to those of the N719 dye (cf. Table 3). The N719 dye achieved an efficiency of $8.05 \%$, which is due to a higher cell current of $17.4 \mathrm{~mA} / \mathrm{cm}^{2}$ compared to the CL1 value of $14.4 \mathrm{~mA} / \mathrm{cm}^{2}$. The difference in cell current can be rationalised in terms of the spectral response of each dye, as exhibited in the IPCE spectra in Figure 7. The N719 dye displayed an increased absorbance over the spectral region $(500-750 \mathrm{~nm})$, resulting in an increase in the overall photocurrent yield. Note that the Si dye has a higher absorbance than N719 in the 400-470 nm region, which may be advantageous depending on the desired DSSC application and lighting conditions, for example, under indoor lighting conditions. It is equally useful for tandem cell configurations, where the light management between the top and bottom cell need to be optimised for obtaining devices with maximum open-circuit voltage and photo-current density.

The possibility of CL1 showing considerable molecular aggregation on the surface of $\mathrm{TiO}_{2}$ cannot be discounted. In fact, the dye-sensitised $\mathrm{TiO}_{2}$ electrode surface shows a strong and attractive red colour, suggesting the possibility of molecular aggregation in a qualitative manner. However, with the limited architectural details available on the packing of the new dye in an adsorbed state over $\mathrm{TiO}_{2}$ at this stage, no conclusive evidence is available to determine the magnitude of molecular aggregation and its dependence on the $\mathrm{TiO}_{2}$ dyeing process itself. Whether a neat monolayer could be obtained on $\mathrm{TiO}_{2}$ surface without any molecular aggregation is also not clear as of now.

3.6. Comparison of CL-1 with Other Silicon-Based Dyes. Lin et al. synthesised a series of dithienosilole dyes (TPCADTS 


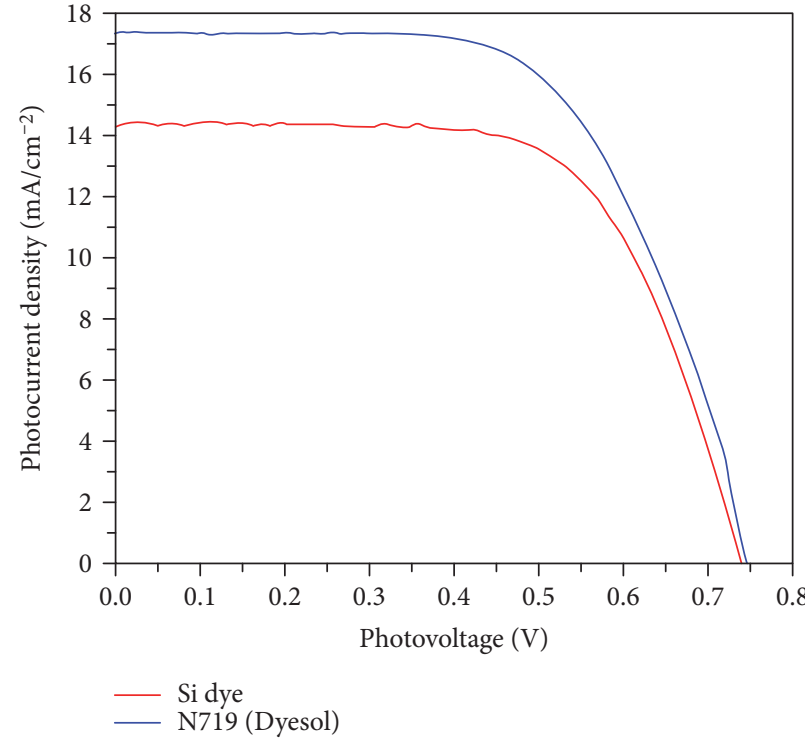

(a)

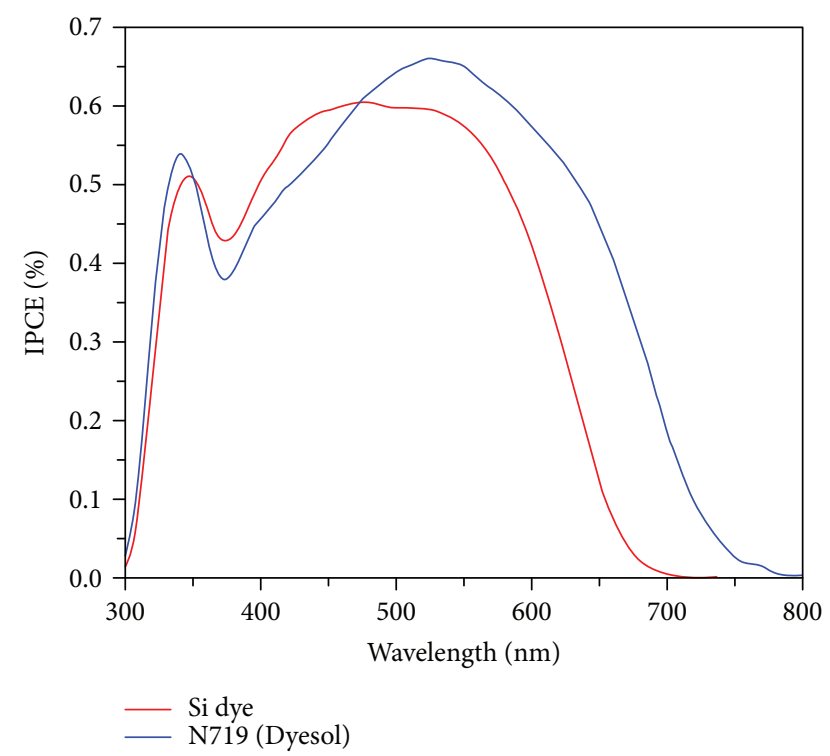

(b)

Figure 7: (a) $J$ - $V$ characteristics of N719 and Si dye (CL-1)-sensitised DSSC under standard AM 1.5 testing conditions. Si dye showed a $V_{\text {oc }}$, $J_{\mathrm{sc}}, \mathrm{FF}$, and $\eta(\%)$ of $0.742,14.4,65$, and 6.90 , respectively. N719 showed a $V_{\mathrm{oc}}, J_{\mathrm{sc}}$, FF, and $\eta(\%)$ of $0.745,17.4,62$, and 8.05, respectively. (b) IPCE spectra of these cells displayed an increased absorbance over the spectral region (500-750 nm) for N719, but a relatively lower absorbance in the $400-470 \mathrm{~nm}$ region compared with Si dye.

and TP6CADTS), which are structurally similar to CL-1 with comparable PCE values [15]. The structures are shown in Figure 8. TPCADTS contained diphenyl-substituted dithienosilole and showed a very similar efficiency of $6.65 \%$. When extra electron donors were added by addition of O-hexyl groups, the efficiency increased to $7.60 \%$. When comparing the more similar TPCADTS with CL-1, it is evident where the improvements lie. The largest improvement lay in the value of $J_{\text {sc }}$ for CL- 1 which increased from 12.7 to $14.4 \mathrm{~mA} / \mathrm{cm}^{2}$ on addition of the dihexyl-substituted dithienosilole core. The values obtained for $V_{\text {oc }}$ remained very similar. It has been reported that on addition of alkyl chains, $V_{\text {oc }}$ can increase; but, both the diphenyl and dihexyl cores had similar effects on the cell performance.

Ko et al. synthesised a series of silole-spaced triarylamine derivatives with an efficiency ranging from $6.73 \%$ to $7.50 \%$ [14]. These dyes also had similar structural features to CL-1. The one major difference which leads to the increase in efficiency in comparison to the CL-1 was that the added bulky electron donation was present in the form of a 3-5'N,N-bis (9,9 dimethylfluorene-2-yl)-phenyl unit (DTS). This dye was named 7b. Diphenyl- rather than dihexylsubstituted dithienosilole was used, and, when combined with the DTS electron-donating group, it had a significantly greater efficiency of $7.50 \%$. Surprisingly enough, the $J_{\text {sc }}$ value decreased to $13.9 \mathrm{~mA} / \mathrm{cm}^{2}$ compared to $14.4 \mathrm{~mA} / \mathrm{cm}^{2}$ for CL-1. No significant difference was observed in the $V_{\text {oc }}$. The increased efficiency of $7 \mathrm{~b}$ likely arises from the superior FF which increased by $9 \%$ compared with CL-1. When a dimethyl group (7a) was used instead of a diphenyl (7b), the efficiency value decreased to $6.73 \%$ which is lower than that of CL1. This suggests that lower aggregation levels were found with CL-1.

\subsection{Molecular Modelling}

3.7.1. Hydrogen-Bonding Dynamics with Ethanol. From the NPT production simulations of classical MD, the persistence times of hydrogen bonding events from hydrogen atoms in ethanol to the carboxylic acid's oxygen atom in the dye were measured. It was found that the hydrogen bonds were short lived and transient, occurring some $4-5 \%$ of the time overall on subpicosecond timescales; the average persistence time, between breakage and possible reformation, was $0.072 \pm 0.023 \mathrm{ps}$. As ethanol molecules underwent self-diffusion in the solvation layer of the dye, and rotational motion therein, the identities of the donors to the carboxylic group oxygen atom change. This underlines the key role of the interactions of the dye with ethanol and also on dye-solvent hydrogen bonding. These frequent dye-solvent hydrogen-bond rearrangements serve to rationalise the potential chemical transformation observed experimentally when placed in ethanol for several days or more.

3.7.2. Spectra of Isolated Systems. Turning to the use of TD-DFT to determine absorption spectra and the underlying transitions, the UV/Vis absorption spectra are provided in Figure 9 for the isolated dye (using the continuum solvation model for ethanol, as discussed earlier).

The experimental UV/Vis absorption spectrum has a maximum absorbance $\left(\lambda_{\max }\right)$ at $468.0 \mathrm{~nm}$. Figure 9 shows the theoretical UV/Vis absorption spectra of the isolated dye as calculated within the B3LYP and the CAM-B3LYP approximations. Using B3LYP, a charge-transfer excitation energy of $618.4 \mathrm{~nm}$ was obtained. On the other hand, the CAM-B3LYP calculation yielded a more accurate result of 


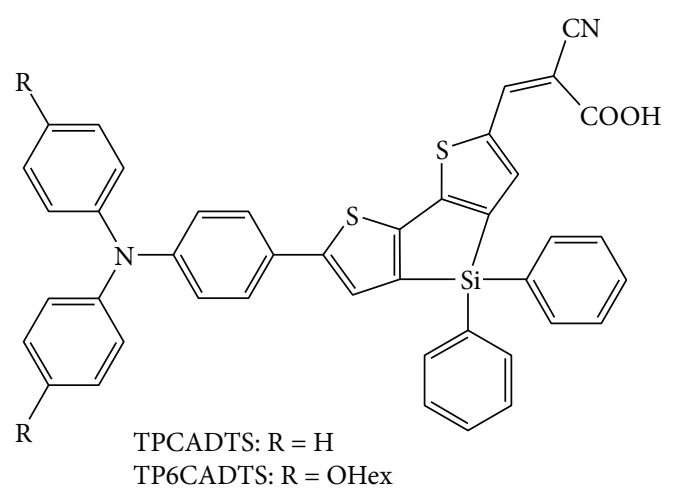

Figure 8: Molecular structures of TPCADTS and TP6CADTS.

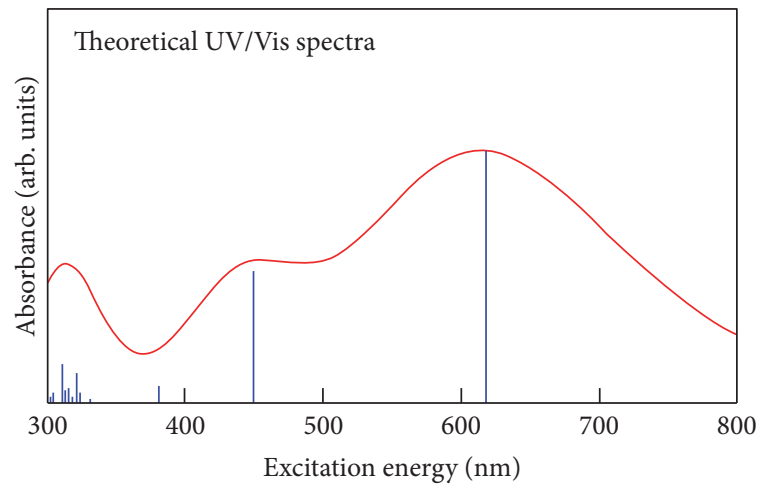

(a) B3LYP

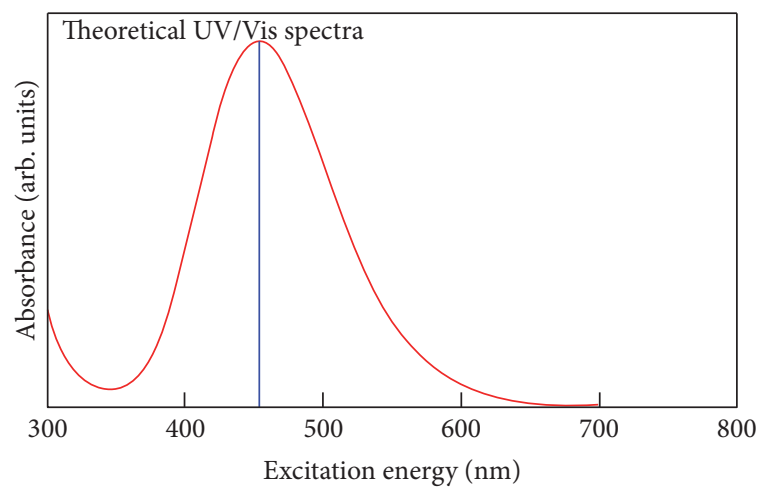

(b) CAM-B3LYP

FIGURE 9: Theoretical UV/Vis spectra of the CL1-dye calculated within the B3LYP approximations to $x c$-functional showing a charge-transfer excitation energy of $618.4 \mathrm{~nm}$ (a) and CAM-B3LYP approximations showing a more accurate result of $453.6 \mathrm{~nm}$ (b).

$453.6 \mathrm{~nm}$. Table 4 summarises these results, providing the values of $\lambda_{\text {max }}$ Th, the positions of $\operatorname{HOMO}(\mathrm{H}), \operatorname{LUMO}(\mathrm{L})$, and the HL gaps, $\Delta_{\mathrm{HL}}=E_{\mathrm{LUMO}}-E_{\mathrm{HOMO}}$ for the dye. It also provides the values of valence band maximum (VBM), conduction band minimum (CBM), and the orbital energy bandgap $\left(E_{\mathrm{g}}\right)$ for the nanoparticle.

Table 5 provides further details for the transition corresponding to $\lambda_{\max }$ Th. The B3LYP results displayed a large error in the excitation energy; therefore, we will focus mainly on CAM-B3LYP results. For CAM-B3LYP, the
TABLE 4: Relevant calculation details for the CL1-dye: wavelength at maximum absorbance $\left(\lambda_{\max }{ }^{\text {Th }}\right)$ and HOMO $(\mathrm{H})$, LUMO (L) positions and $\mathrm{H}-\mathrm{L}$ gap $\left(\Delta_{\mathrm{HL}}=E_{\mathrm{LUMO}}-E_{\mathrm{HOMO}}\right)$. For titania, we have reported the lowest transition valence band maximum (VBM) and the conduction band minimum (CBM) as well as the orbital-energy bandgap $\left(E_{\mathrm{g}}\right)$.

\begin{tabular}{lccccc}
\hline \multirow{2}{*}{ System } & Approx. & $\begin{array}{c}\lambda_{\max }^{\text {Th }} \\
\mathrm{eV}(\mathrm{nm})\end{array}$ & $\mathrm{H}(\mathrm{eV})$ & $\mathrm{L}(\mathrm{eV})$ & $\Delta_{\mathrm{HL}}(\mathrm{eV})$ \\
\hline \multirow{2}{*}{$\mathrm{CL} 1$} & B3LYP & $2.0(618.4)$ & -5.0 & -2.8 & 2.3 \\
& CAM-B3LYP & $2.7(453.6)$ & -6.2 & -1.7 & 4.6 \\
\hline \multirow{2}{*}{ System } & \multirow{2}{*}{ Approx. } & $\begin{array}{c}\text { 1st trans. } \\
\mathrm{eV}(\mathrm{nm})\end{array}$ & $\begin{array}{c}\mathrm{VBM} \\
(\mathrm{eV})\end{array}$ & $\begin{array}{c}\mathrm{CBM} \\
(\mathrm{eV})\end{array}$ & \multirow{2}{*}{$E_{\mathrm{g}}(\mathrm{eV})$} \\
\hline \multirow{2}{*}{$\mathrm{TiO}_{2}$} & B3LYP & $3.8(326.3)$ & -7.5 & -3.0 & 4.5 \\
& CAM-B3LYP & $4.4(279.9)$ & -9.2 & -1.7 & 7.6 \\
\hline
\end{tabular}

TABLE 5: Transition corresponding to $\lambda_{\max }^{\text {Th }}$ for the CL1 dye within B3LYP and CAM-B3LYP: T.E.: transition energy $\left(=\lambda_{\max }{ }^{\mathrm{Th}}\right)$ in $\mathrm{eV}$; O.S.: oscillator strength; and Coeff.: the magnitude of the configuration interaction singles coefficients. The most prominent transitions (indicated by the magnitude of the configuration interaction singles coefficients) are highlighted in bold.

\begin{tabular}{|c|c|c|}
\hline Approx. & T.E. (O.S.) (eV) & Involved orbitals (Coeff.) \\
\hline (1) B3LYP & $2.0(1.17)$ & $\mathrm{H} \rightarrow \mathrm{L}(0.71)$ \\
\hline (2) CAM-B3LYP & $2.7(1.65)$ & $\begin{array}{c}\mathbf{H} \rightarrow \mathbf{L}(\mathbf{0 . 5 7}), \mathrm{H}-1 \rightarrow \mathrm{L}(0.37) \\
\mathrm{H} \rightarrow \mathrm{L}+1(0.14)\end{array}$ \\
\hline
\end{tabular}

transition upon photoexcitation involves several promotions between the occupied and empty orbital pairs. However, the most prominent promotion (indicated by the magnitude of the configuration interaction singles coefficients) corresponds to the one from the highest occupied molecular orbital (HOMO) to the lowest unoccupied molecular orbitals (LUMO).

Figure 10 shows the isosurface plots (isovalue $=0.2 \mathrm{e} / \mathrm{a} . \mathrm{u}^{3}{ }^{3}$ ) of the various MOs involved in the photoexcitation. The results show that the HOMO of the dye is delocalised over the entire molecule, with somewhat more localisation on the donor group compared to the acceptor group. In contrast, the LUMO of the dye is predominantly localised on the acceptor and the linker/spacer groups. In turn, this implies that there will be sufficient charge separation upon excitation, thereby, reducing the rate of charge recombination.

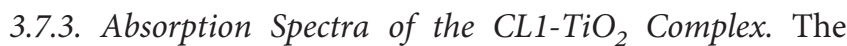
excited-state properties of the dye-titania complex were modelled using the CAM-B3LYP approximation. CAMB3LYP was utilised as it outperforms B3LYP in its description of the excited-state properties of the dye molecule, which is the photoactive subsystem in the complex; this superior performance of CAM-B3LYP was shown in the previous discussion of the isolated dye (cf. Tables 4 and 5 and Figures 10 and 11). To create a computer model of the dyetitania complex, the dye molecule was chemisorbed in silico onto the nanoparticle. This was accomplished by the removal of the hydrogen atom from the carboxylic acid anchor and 


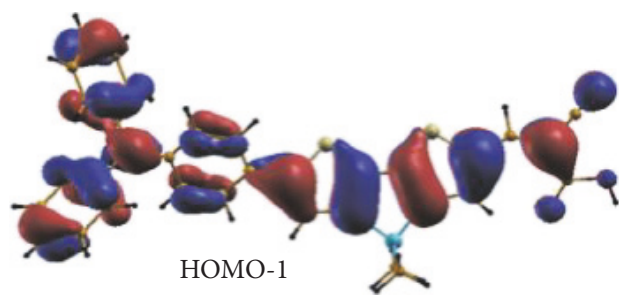

(a)

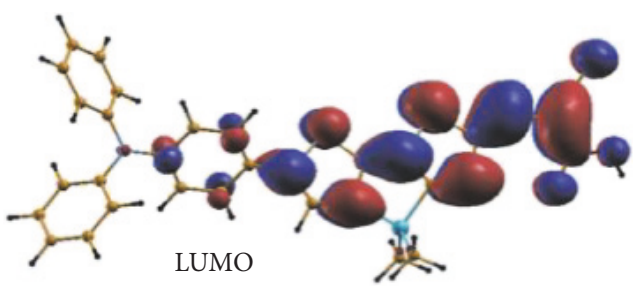

(c)

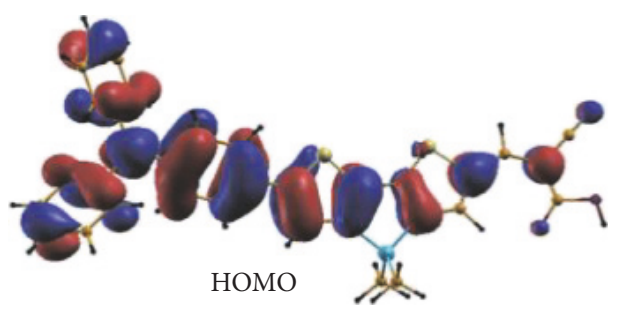

(b)

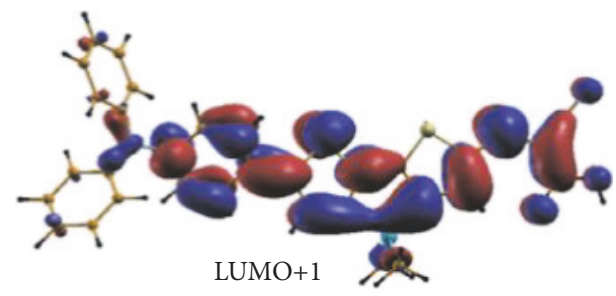

(d)

Figure 10: Isosurface plots (isovalue $=0.2 \mathrm{e}$ e/a.u. ${ }^{3}$ ) for the molecular orbitals involved in the photoexcitation of the CL1-dye. The orbitals were calculated within CAM-B3LYP.

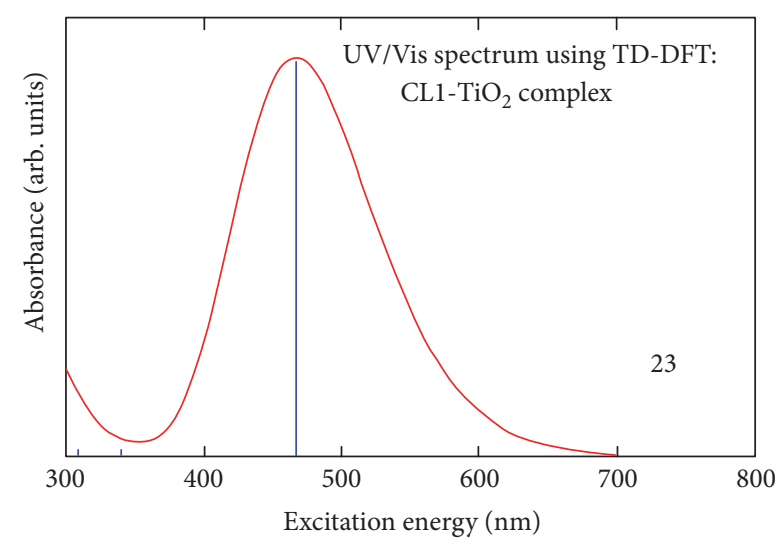

Figure 11: UV/Vis spectrum using TD-DFT of CL1- $\mathrm{TiO}_{2}$ complex calculated within the CAM-B3LYP approximation, showing individual transitions as impulses with maximum absorbance values of $436.0 \mathrm{~nm}$ and $467.4 \mathrm{~nm}$.

binding the two carboxylate oxygen atoms with two fivefold coordinated titanium atoms on the surface of the titania nanoparticle. The hydrogen atom removed was transferred to an undercoordinated oxygen atom on the titania surface to maintain the neutrality of the system, which was essential for the TD-DFT calculations. The resulting structure was relaxed within CAM-B3LYP. This optimised structure was then used to study the excited-state properties of the complex using TD-DFT.

Figure 11 shows the UV/Vis spectra for the complex as calculated using TD-DFT. The experimental and calculated values of the energy for maximum absorbance are in very good agreement at about $436.0 \mathrm{~nm}(2.8 \mathrm{eV})$ and $467.4 \mathrm{~nm}$ $(2.7 \mathrm{eV})$, respectively.

Details of the most important transition corresponding to $\lambda_{\max }{ }^{\text {Th }}$ and the involved orbital pairs are provided in Table 6. Figure 12 shows the molecular orbitals of the complex involved in the transition (HOMO-1 orbital is not
TABLE 6: Details of the most important transition $\left(=\lambda_{\max }{ }^{\text {Th. }}\right)$ for the dye-titania complex. The calculations were done within the CAMB3LYP approximation. Abbreviations and the use of bold font are as that of Table 5 .

\begin{tabular}{lcc}
\hline System & T.E. (eV) (O.S.) & Involved orbitals (Coeff.) \\
\hline \multirow{2}{*}{$\mathrm{CL}^{-}-\mathrm{TiO}_{2}$} & 2.7 & $\mathrm{H}-1 \rightarrow \mathrm{L}(0.38)$ \\
& $(1.77)$ & $\mathbf{H} \rightarrow \mathbf{L} \mathbf{( 0 . 5 5 )}$ \\
\hline
\end{tabular}

shown here; it is mostly derived from the dye's HOMO-1). From the isosurface plots, both HOMO and LUMO are predominantly localised on the dye molecule itself. However, the LUMO does show some hybridisation between the dyes LUMO and the $d$-orbitals of the titanium atoms at the surface. Such a result, where the only empty state involved is the LUMO of the complex, may indicate that only a direct transition is possible for the complex. However, it is difficult to pinpoint the precise mechanism in this case. This is due to the fact that although CAMB3LYP improves the description of the photophysics of the isolated dye, it overestimates the bandgap of the titania nanoparticle. In turn, this results in a misalignment of dye states with regard to the valence and conduction bands of the titania nanoparticle; hence, there is an absence of a titania-derived conduction band manifold below the dye's LUMO. Clearly, it is difficult to obtain an accurate value for the charge-transfer excitation energy of the isolated dye and the dye-titania complex, whilst also getting a reasonable level alignment (at least within the $x c$-functionals explored here). The latter is important for the accurate description of the charge-transfer mechanism(s), and this is discussed further in [61].

\section{Conclusions}

The CL1 dye containing a silicon bridge showed a good light to electricity efficiency of $6.90 \%$. The Si dye exhibited better 


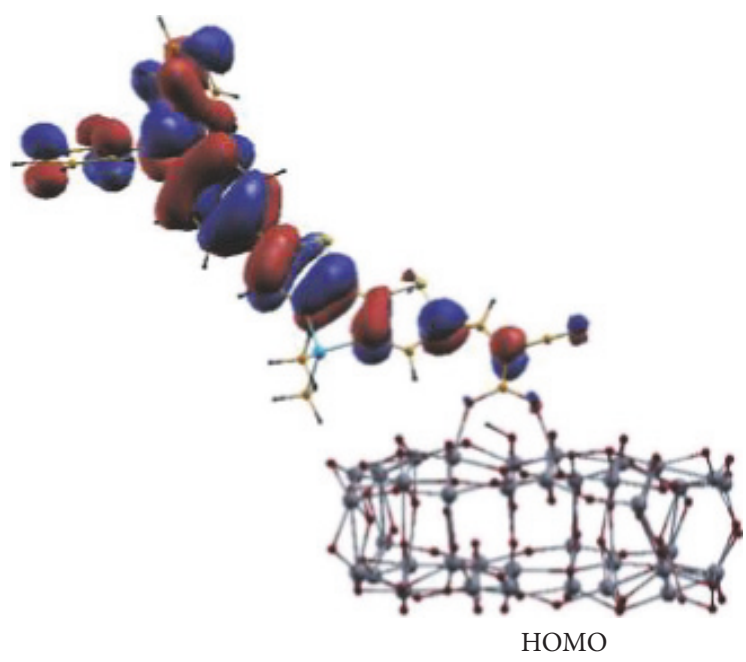

(a)

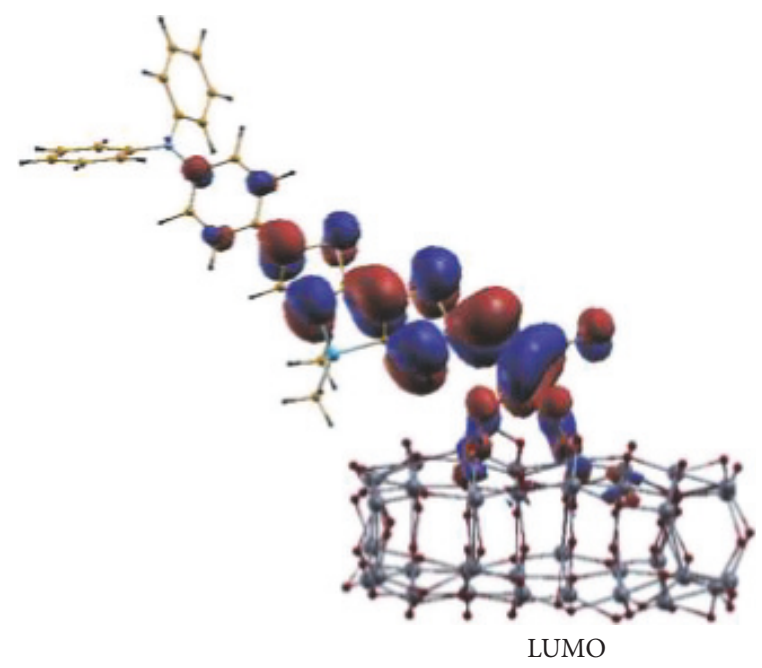

(b)

FIgURE 12: Molecular orbitals of $\mathrm{CL} 1-\mathrm{TiO}_{2}$ complex involved in the most important transitions (HOMO and LUMO).

performance than N719 in the $400-470 \mathrm{~nm}$ region, which may be advantageous depending on the desired DSSC application and lighting conditions. CL-1 compares well with other Si-based dyes [9, 10], which achieve efficiencies of around $7.5 \%$. Also, this is generally superior in performance than rival nanorod-based solar technologies [62] or DSSC approaches exploiting dye coverage with cobalt-based electrolytes [63]. From the view point of TD-DFT, the (conjectured) possibility that only a direct transition may take place due to some hybridisation between the LUMO of the dye and surface $\mathrm{Ti}$ atoms in the complexed state may limit the extent of photo-excited transition in the present dye-this may serve to rationalise why the observed overall energy conversion efficiency is not perhaps as high as the previously reported Si-based dyes. However, this conclusion is somewhat tentative, given that partial LUMO hybridisation does not necessarily preclude additional indirect transitions. These dyes are eventually useful for certain indoor applications where the spectral availability matches with the dye's absorption spectrum as well as for building tandem DSSC devices with optimal light management in order to obtain maximum short-circuit current densities. From classical MD simulations, it was evident that ethanol-formed hydrogen bonds and other dispersive and Coulombic interactions with the dye in dissolved state compromise its stability in solution form, whilst TD-DFT has provided a good agreement with the experimental data for prediction of optical absorption and identification of the underlying transitions responsible. Further work has been done on the addition of donor groups and will be presented in a later paper.

\section{Disclosure}

Pratibha Dev's current address is at Department of Physics and Astronomy, Howard University, Washington, DC 20059, USA, and Praveen K. Surolia's current address is at Department of Chemistry, Manipal University Jaipur, Rajasthan, India.

\section{Conflicts of Interest}

The authors declare that they have no conflicts of interest.

\section{Acknowledgments}

This material is based upon work supported by the Science Foundation Ireland under Grant no. [07/SRC/B1160]. K. Ravindranathan Thampi acknowledges the support received under SFI-Airtricity-Funded SFI-Stokes professorship grant and the SMARTOP project (Grant no. 265769) financed by the EC-FP7 programme. The authors acknowledge the computational support provided by the Irish Centre for High-End Computing (ICHEC). Neelima Rathi and Edmond Magner acknowledge support from the HEA-funded PRTLI4 programme, INSPIRE. Pratibha Dev and Praveen K. Surolia acknowledge the financial support for this work through EMPOWER fellowships granted by the Irish Research Council for Science and Engineering (IRCSET).

\section{References}

[1] B. O'Regan and M. Grätzel, "A low-cost, high-efficiency solar cell based on dye-sensitized," Nature, vol. 353, no. 6346, pp. 737-740, 1991.

[2] R. Komiya, A. Fukui, N. Murofushi, N. Koide, R. Yamanaka, and H. Katayama, Technical Digest, 21st International Photovoltaic Science and Engineering Conference, Fukuoka, November 2011, 2 C-5O-08.

[3] M. A. Green, K. Emery, Y. Hishikawa, W. Warta, and E. D. Dunlop, "Solar cell efficiency tables (version 45)," Progress in Photovoltaics, vol. 23, no. 1, pp. 1-9, 2015.

[4] H. Imahori, T. Umeyama, and S. Ito, "Large $\pi$-aromatic molecules as potential sensitizers for highly efficient dyesensitized solar cells," Accounts of Chemical Research, vol. 42, no. 11, pp. 1809-1818, 2009.

[5] A. Yella, H. W. Lee, H. N. Tsao et al., "Porphyrin-sensitized solar cells with cobalt (II/III)-based redox electrolyte 
exceed 12 percent efficiency," Science, vol. 334, no. 6056, pp. 629-634, 2011.

[6] S. Mathew, A. Yella, P. Gao et al., "Dye-sensitized solar cells with $13 \%$ efficiency achieved through the molecular engineering of porphyrin sensitizers," Nature Chemistry, vol. 6, no. 3, pp. 242-247, 2014.

[7] K. Kakiage, Y. Aoyama, T. Yano, K. Oya, J. Fujisawa, and M. Hanaya, "Highly-efficient dye-sensitized solar cells with collaborative sensitization by silyl-anchor and carboxyanchor dyes," Chemical Communications, vol. 51, no. 88, pp. 15894-15897, 2015.

[8] J. N. Clifford, G. Yahioglu, L. R. Milgrom, and J. R. Durrant, "Molecular control of recombination dynamics in dye sensitised nanocrystalline TiO 2 films," Chemical Communications, no. 12, pp. 1260-1261, 2002.

[9] T. Bessho, S. M. Zakeeruddin, C. Y. Yeh, E. W. G. Diau, and M. Grätzel, "Highly efficient mesoscopic dye-sensitized solar cells based on donor-acceptor-substituted porphyrins," Angewandte Chemie, International Edition, vol. 49, no. 37, pp. 6646-6649, 2010.

[10] S. M. Feldt, E. A. Gibson, E. Gabrielsson, L. Sun, G. Boschloo, and A. Hagfeldt, "Design of organic dyes and cobalt polypyridine redox mediators for high-efficiency dye-sensitized solar cells," Journal of the American Chemical Society, vol. 132, no. 46, pp. 16714-16724, 2010.

[11] H. N. Tsao, C. Yi, T. Moehl et al., "Cyclopentadithiophene bridged donor-acceptor dyes achieve high power conversion efficiencies in dye-sensitized solar cells based on the triscobalt bipyridine redox couple," ChemSusChem, vol. 4, no. 5, pp. 591-594, 2011.

[12] L. Liao, A. Cirpan, Q. Chu, F. E. Karasz, and Y. Pang, "Synthesis and optical properties of light-emitting $\pi$-conjugated polymers containing biphenyl and dithienosilole," Journal of Polymer Science Part A: Polymer Chemistry, vol. 45, no. 10, pp. 2048-2058, 2007.

[13] T.-Y. Chu, J. Lu, S. Beaupré et al., "Effects of the molecular weight and the side-chain length on the photovoltaic performance of dithienosilole/thienopyrrolodione copolymers," Advanced Functional Materials, vol. 22, no. 11, pp. 23452351, 2012.

[14] S. Ko, H. Choi, M.-S. Kang et al., "Silole-spaced triarylamine derivatives as highly efficient organic sensitizers in dyesensitized solar cells (DSSCs)," Journal of Materials Chemistry, vol. 20, no. 12, pp. 2391-2399, 2010.

[15] L.-Y. Lin, C.-H. Tsai, K.-T. Wong et al., "Organic dyes containing coplanar diphenyl-substituted dithienosilole core for efficient dye-sensitized solar cells," The Journal of Organic Chemistry, vol. 75, no. 14, pp. 4778-4785, 2010.

[16] M. J. Ross and K. R. William, Impedance spectroscopy, Wiley, New York, 1987.

[17] J. Bisquert, "Theory of the impedance of charge transfer via surface states in dye-sensitized solar cells," Journal of Electroanalytical Chemistry, vol. 646, no. 1-2, pp. 43-51, 2010.

[18] L. Andrade, R. Cruz, H. Ribeiro, and A. Mendes, "Impedance characterization of dye-sensitized solar cells in a tandem arrangement for hydrogen production by water splitting," International Journal of Hydrogen Energy, vol. 35, no. 17, pp. 8876-8883, 2010.

[19] F. Fabregat-Santiago, J. Bisquert, E. Palomares et al., "Correlation between photovoltaic performance and impedance spectroscopy of dye-sensitized solar cells based on ionic liquids," Journal of Physical Chemistry C, vol. 111, no. 17, pp. 6550-6560, 2007.

[20] R. Kern, R. Sastrawan, J. Ferber, R. Stangl, and J. Luther, "Modeling and interpretation of electrical impedance spectra of dye solar cells operated under open-circuit conditions," Electrochimica Acta, vol. 47, no. 26, pp. 4213-4225, 2002.

[21] S. Ito, T. N. Murakami, P. Comte et al., "Fabrication of thin film dye sensitized solar cells with solar to electric power conversion efficiency over 10\%," Thin Solid Films, vol. 516, no. 14, pp. 4613-4619, 2008.

[22] S. Ito, P. Chen, P. Comte et al., "Fabrication of screen-printing pastes from TiO2 powders for dye-sensitised solar cells," Progress in Photovoltaics Research and Applications, vol. 15, no. 7, pp. 603-612, 2007.

[23] G. Lu, H. Usta, C. Risko et al., "Synthesis, characterization, and transistor response of semiconducting silole polymers with substantial hole mobility and air stability. Experiment and theory," Journal of the American Chemical Society, vol. 130, no. 24, pp. 7670-7685, 2008.

[24] J. M. Kroon, N. J. Bakker, H. J. P. Smit et al., "Nanocrystalline dye-sensitized solar cells having maximum performance," Progress in Photovoltaics Research and Applications, vol. 15, no. 1, pp. 1-18, 2007.

[25] M. Frisch, G. Trucks, H. Schlegel et al., "Semiempirical GGA-type density functional constructed with a long-range dispersion correction," Journal of Computational Chemistry, vol. 27, no. 15, pp. 1787-1799, 2006.

[26] M. J. G. Peach, P. Benfield, T. Helgaker, and D. J. Tozer, "Excitation energies in density functional theory: an evaluation and a diagnostic test," The Journal of Chemical Physics, vol. 128, no. 4, p. 044118, 2008.

[27] P. Dev, S. Agrawal, and N. J. English, "Determining the appropriate exchange-correlation functional for time-dependent density functional theory studies of charge-transfer excitations in organic dyes," The Journal of Chemical Physics, vol. 136, no. 22, p. 224301, 2012.

[28] A. D. Becke, "Density-functional thermochemistry. III. The role of exact exchange," The Journal of Chemical Physics, vol. 98, no. 7, pp. 5648-5652, 1993.

[29] R. Kavathekar, P. Dev, N. J. English, and J. M. D. MacElroy, "Molecular dynamics study of water in contact with $\mathrm{TiO}_{2}$ rutile-110, 100, 101, 001 and anatase-101, 001 surfaces," Molecular Physics, vol. 109, no. 13, pp. 1649-1656, 2011.

[30] P. J. Stephens, F. J. Devlin, C. S. Ashvar, C. F. Chabalowski, and M. J. Frisch, "Theoretical calculation of vibrational circular dichroism spectra," Faraday Discussions, vol. 99, pp. 103119, 1994.

[31] T. Yanai, D. P. Tew, and N. C. Handy, "A new hybrid exchange-correlation functional using the Coulombattenuating method (CAM-B3LYP)," Chemical Physics Letters, vol. 393, no. 1-3, pp. 51-57, 2004.

[32] M. Cossi, N. Rega, G. Scalmani, and V. Barone, "Energies, structures, and electronic properties of molecules in solution with the C-PCM solvation model," Journal of Computational Chemistry, vol. 24, no. 6, pp. 669-681, 2003.

[33] P. Persson, R. Bergström, and S. Lunell, "Quantum chemical study of photoinjection processes in dye-sensitized $\mathrm{TiO} 2$ nanoparticles," The Journal of Physical Chemistry. B, vol. 104, no. 44, pp. 10348-10351, 2000.

[34] F. De Angelis, A. Tilocca, and A. Selloni, "Time-dependent DFT study of $[\mathrm{Fe}(\mathrm{CN}) 6]$ 4-sensitization of $\mathrm{TiO} 2$ 
nanoparticles," Journal of the American Chemical Society, vol. 126, no. 46, pp. 15024-15025, 2004.

[35] F. De Angelis, "Direct vs. indirect injection mechanisms in perylene dye-sensitized solar cells: a DFT/TDDFT investigation," Chemical Physics Letters, vol. 493, no. 4-6, pp. 323327,2010 .

[36] S. Agrawal, P. Dev, N. J. English, K. R. Thampi, and J. MacElroy, "First-principles study of the excited-state properties of coumarin-derived dyes in dye-sensitized solar cells," Journal of Materials Chemistry, vol. 21, no. 30, pp. 1110111108, 2011.

[37] S. Agrawal, P. Dev, N. J. English, K. R. Thampi, and J. MacElroy, "A TD-DFT study of the effects of structural variations on the photochemistry of polyene dyes," Chemical Science, vol. 3, no. 2, pp. 416-424, 2012.

[38] T. A. Halgren, "Merck molecular force field. I. Basis, form, scope, parameterization, and performance of MMFF94," Journal of Computational Chemistry, vol. 17, no. 5-6, pp. 490-519, 1996.

[39] MOE, The Molecular Operating Environment from Chemical Computing Group Inc..

[40] N. J. English and J. M. D. MacElroy, "Atomistic simulations of liquid water using Lekner electrostatics," Molecular Physics, vol. 100, no. 23, pp. 3753-3769, 2002.

[41] N. J. English, "Effect of electrostatics techniques on the estimation of thermal conductivity via equilibrium molecular dynamics simulation: application to methane hydrate," Molecular Physics, vol. 106, no. 15, pp. 1887-1898, 2008.

[42] M. Xu, S. Wenger, H. Bala et al., "Tuning the energy level of organic sensitizers for high-performance dye-sensitized solar cells," Journal of Physical Chemistry C, vol. 113, no. 7, pp. 2966-2973, 2009.

[43] M. P. Allen and D. J. Tildesley, Molecular Simulation of Liquids, Clarendon, Oxford.

[44] S. Roquet, A. Cravino, P. Leriche, O. Alévêque, P. Frère, and J. Roncali, "Triphenylamine-thienylenevinylene hybrid systems with internal charge transfer as donor materials for heterojunction solar cells," Journal of the American Chemical Society, vol. 128, no. 10, pp. 3459-3466, 2006.

[45] J. H. Yum, D. P. Hagberg, S. J. Moon et al., "A light-resistant organic sensitizer for solar-cell applications," Angewandte Chemie (International Edition in English), vol. 48, no. 9, pp. 1576-1580, 2009.

[46] A. Hagfeldt and M. Gratzel, "Light-induced redox reactions in nanocrystalline systems," Chemical Reviews, vol. 95, no. 1, pp. 49-68, 1995.

[47] C. Klein, M. K. Nazeeruddin, P. Liska et al., "Engineering of a novel ruthenium sensitizer and its application in dyesensitized solar cells for conversion of sunlight into electricity," Inorganic Chemistry, vol. 44, no. 2, pp. 178-180, 2004.

[48] C. Teng, X. Yang, C. Yang et al., "Influence of triple bonds as $\pi$-spacer units in metal-free organic dyes for dye-sensitized solar cells," Journal of Physical Chemistry C, vol. 114, no. 25, pp. 11305-11313.

[49] D. Shi, Y. Cao, N. Pootrakulchote et al., "New organic sensitizer for stable dye-sensitized solar cells with solvent-free ionic liquid electrolytes," Journal of Physical Chemistry C, vol. 112, no. 44, pp. 17478-17485, 2008.

[50] R. M. Silverstein, G. C. Bassler, and T. C. Morrill, Spectrometric identification of organic compounds, 1974.
[51] M. K. Nazeeruddin, R. Humphry-Baker, D. L. Officer, W. M. Campbell, A. K. Burrell, and M. Gratzel, "Application of metalloporphyrins in nanocrystalline dye-sensitized solar cells for conversion of sunlight into electricity," Langmuir, vol. 20, no. 15, pp. 6514-6517, 2004.

[52] G. B. Deacon and R. J. Phillips, "Relationships between the carbon-oxygen stretching frequencies of carboxylato complexes and the type of carboxylate coordination," Coordination Chemistry Reviews, vol. 33, no. 3, pp. 227-250, 1980.

[53] A. Vittadini, A. Selloni, F. P. Rotzinger, and M. Gratzel, "Formic acid adsorption on dry and hydrated $\mathrm{TiO} 2$ anatase (101) surfaces by DFT calculations," The Journal of Physical Chemistry. B, vol. 104, no. 6, pp. 1300-1306, 2000.

[54] J. Bisquert, F. Fabregat-Santiago, I. Mora-Sero, G. GarciaBelmonte, and S. Giménez, "Electron lifetime in dye-sensitized solar cells: theory and interpretation of measurements," Journal of Physical Chemistry C, vol. 113, no. 40, pp. 17278-17290, 2009.

[55] Q. Wang, J.-E. Moser, and M. Grätzel, "Electrochemical impedance spectroscopic analysis of dye-sensitized solar cells," The Journal of Physical Chemistry B, vol. 109, no. 31, pp. 14945-14953, 2005.

[56] L. Han, N. Koide, Y. Chiba, and T. Mitate, "Modeling of an equivalent circuit for dye-sensitized solar cells," Applied Physics Letters, vol. 84, no. 13, pp. 2433-2435, 2004.

[57] J. Halme, P. Vahermaa, K. Miettunen, and P. Lund, "Device physics of dye solar cells," Advanced Materials, vol. 22, no. 35, pp. 22E210-E234, 2010.

[58] L.-L. Li, Y.-C. Chang, H.-P. Wu, and E. W.-G. Diau, "Characterisation of electron transport and charge recombination using temporally resolved and frequency-domain techniques for dye-sensitised solar cells," International Reviews in Physical Chemistry, vol. 31, no. 3, pp. 420-467, 2012.

[59] N. J. English and D. G. Carroll, “Prediction of Henry's Law constants by a Quantitative Structure Property Relationship and neural networks," Journal of Chemical Information and Computer Sciences, vol. 41, no. 5, pp. 1150-1161, 2001.

[60] M. Adachi, M. Sakamoto, J. Jiu, Y. Ogata, and S. Isoda, "Determination of parameters of electron transport in dye-sensitized solar cells using electrochemical impedance spectroscopy," The Journal of Physical Chemistry. B, vol. 110, no. 28, pp. 13872-13880, 2006.

[61] P. Dev, S. Agrawal, and N. J. English, "Functional assessment for predicting charge-transfer excitations of dyes in complexed state: a study of triphenylamine-donor dyes on titania for dye-sensitized solar cells," The Journal of Physical Chemistry. A, vol. 117, no. 10, pp. 2114-2124, 2013.

[62] A. Singh, N. J. English, and K. M. Ryan, "Highly ordered nanorod assemblies extending over device scale areas and in controlled multilayers by electrophoretic deposition," The Journal of Physical Chemistry. B, vol. 117, no. 6, pp. 1608-1615, 2013.

[63] M. Pazoki, P. W. Lohse, N. Taghavinia, A. Hagfeldt, and G. Boschloo, "The effect of dye coverage on the performance of dye-sensitized solar cells with a cobalt-based electrolyte," Physical Chemistry Chemical Physics, vol. 16, no. 18, pp. 8503-8508, 2014. 

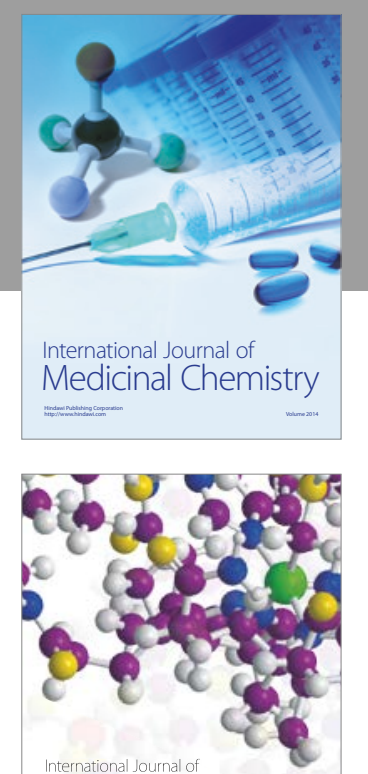

Carbohydrate Chemistry

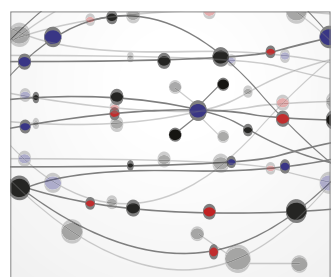

The Scientific World Journal
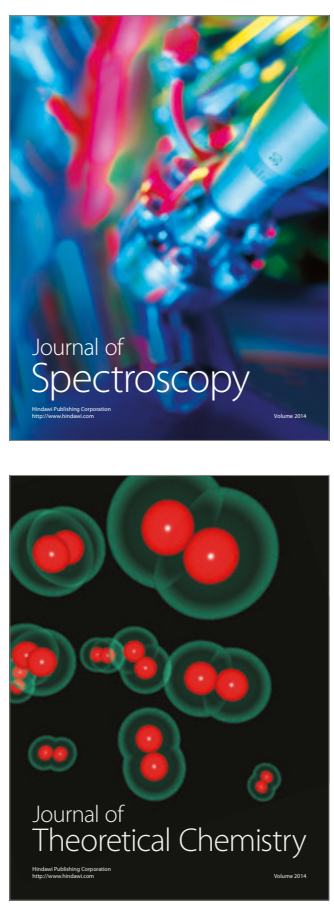
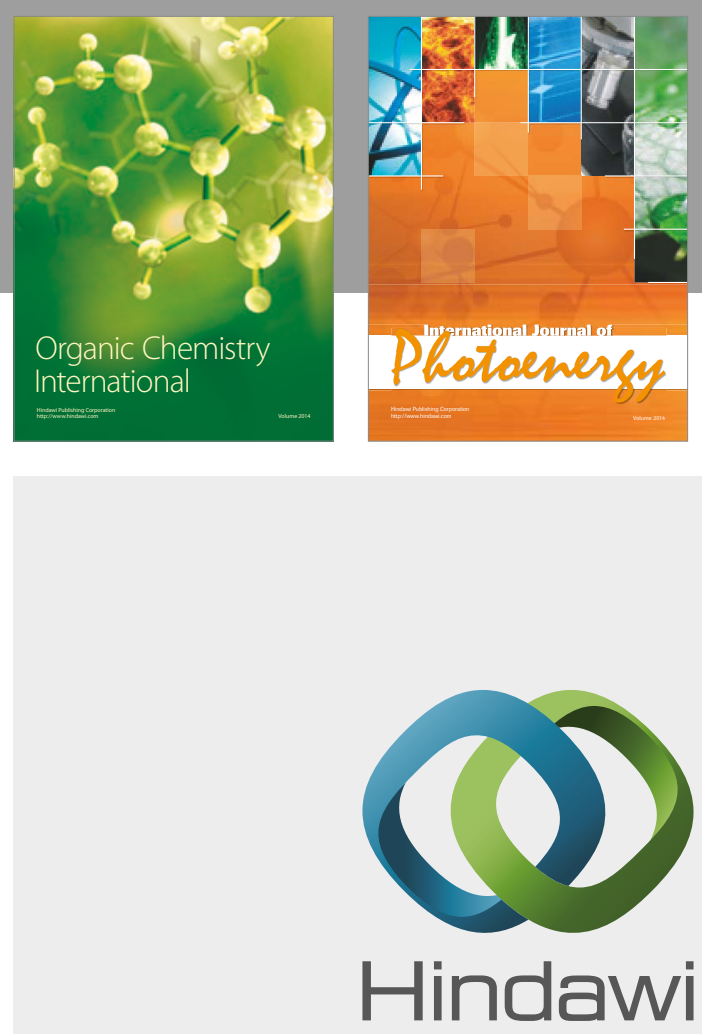

Submit your manuscripts at

https://www.hindawi.com

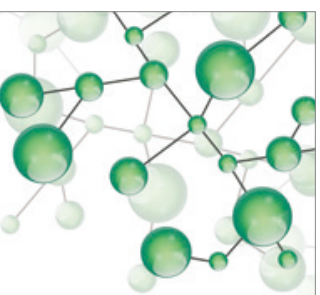

International Journal of

Inorganic Chemistry

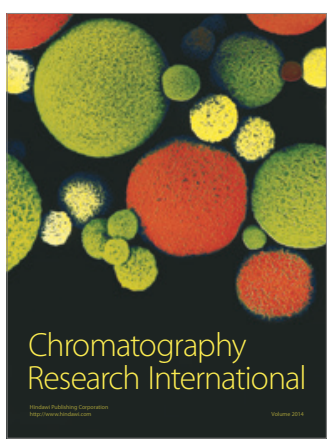

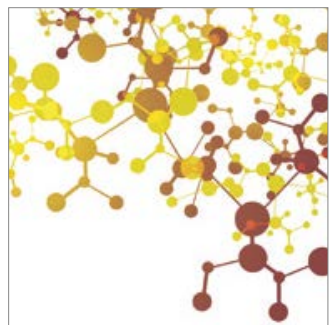

Applied Chemistry
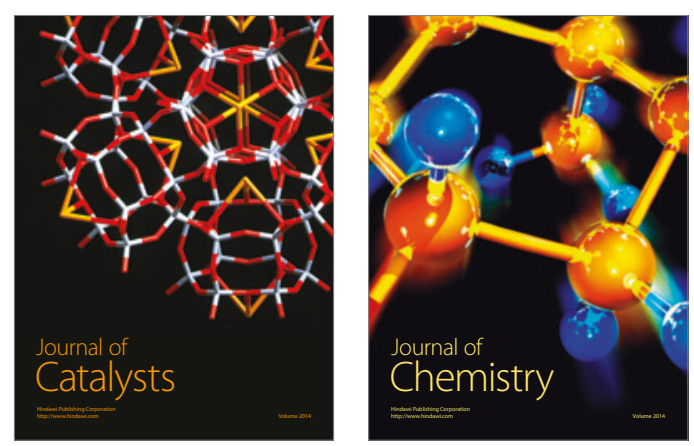
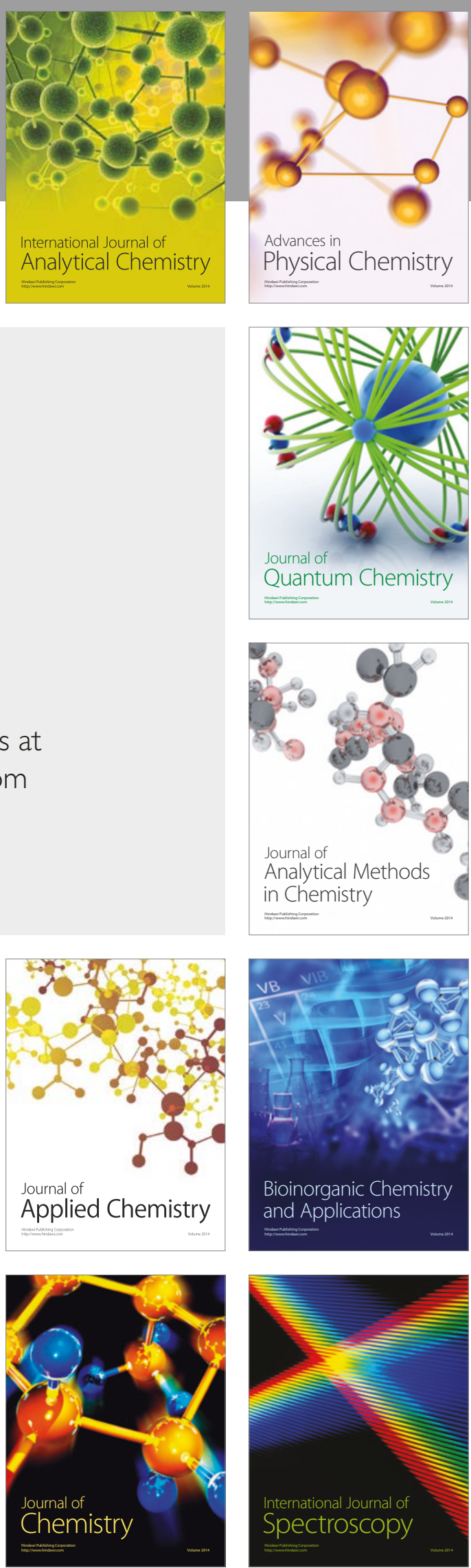